\title{
Neutrophil Heterogeneity in Cancer: From Biology to Therapies
}

\author{
Pacôme Lecot ${ }^{1}$, Matthieu Sarabi ${ }^{1}$, Manuela Pereira Abrantes ${ }^{1}$, Julie Mussard ${ }^{1}$, \\ Leo Koenderman ${ }^{2}$, Christophe Caux ${ }^{1}$, Nathalie Bendriss-Vermare ${ }^{1}$ and \\ Marie-Cécile Michallet ${ }^{1 *}$
}

\begin{abstract}
1 Department of Immunity, Virus, and Inflammation (IVI), Centre de Recherche en Cancérologie de Lyon, Centre Léon Bérard, University of Lyon, Université Claude Bernard Lyon 1, INSERM 1052, CNRS 5286, Lyon, France, ${ }^{2}$ Department of Respiratory Medicine and Center of Translational Immunology, University Medical Center Utrecht, Utrecht, Netherlands
\end{abstract}

\section{OPEN ACCESS}

Edited by:

Christian Jan Lood,

University of Washington,

United States

Reviewed by:

Sven Brandau,

University of

Duisburg-Essen, Germany

Maria Rosaria Galdiero,

University of Naples Federico II, Italy

*Correspondence:

Marie-Cécile Michallet

marie-cecile.michallet@ Iyon.unicancer.fr

Specialty section:

This article was submitted to

Cancer Immunity and Immunotherapy,

a section of the journal

Frontiers in Immunology

Received: 20 May 2019 Accepted: 28 August 2019

Published: 20 September 2019

Citation:

Lecot $P$, Sarabi M, Pereira Abrantes M, Mussard J, Koenderman L, Caux C,

Bendriss-Vermare $\mathrm{N}$ and Michallet M-C (2019) Neutrophil Heterogeneity in Cancer: From

Biology to Therapies.

Front. Immunol. 10:2155.

doi: 10.3389/fimmu.2019.02155
Neutrophils have been extensively described in the pathophysiology of autoimmune and infectious diseases. Accumulating evidence also suggests the important role of neutrophils in cancer progression through their interaction with cancer and immune cells in blood and in the tumor microenvironment (TME). Most studies have described neutrophils as key drivers of cancer progression, due to their involvement in various tumor promoting functions including proliferation, aggressiveness, and dissemination, as well as in immune suppression. However, such studies were focusing on late-stages of tumorigenesis, in which chronic inflammation had already developed. The role of tumor-associated neutrophils (TANs) at early stages of tumor development remains poorly described, though recent findings indicate that early-stage TANs may display anti-tumor properties. Beyond their role at tumor site, evidence supported by NLR retrospective studies and functional analyses suggest that blood neutrophils could also actively contribute to tumorigenesis. Hence, it appears that the phenotype and functions of neutrophils vary greatly during tumor progression, highlighting their heterogeneity. The origin of pro- or anti-tumor neutrophils is generally believed to arise following a change in cell state, from resting to activated. Moreover, the fate of neutrophils may also involve distinct differentiation programs yielding various subsets of pro or anti-tumor neutrophils. In this review, we will discuss the current knowledge on neutrophils heterogeneity across different tissues and their impact on tumorigenesis, as well as neutrophil-based therapeutic strategies that have shown promising results in pre-clinical studies, paving the way for the design of neutrophil-based next generation immunotherapy.

Keywords: neutrophil (PMN), cancer, immunotherapy, MDSC (myeloid-derived suppressor cells), G-MDSC (granulocytic MDSC), tumor-associated neutrophils (TANs), subsets

\section{CIRCULATING NEUTROPHILS IN CANCER}

Aside from the molecular signals driving cancer, several studies have demonstrated the contribution of the host-driven inflammatory response to tumor progression and/or to treatment outcome (1-4). Neutrophils are key players in the inflammatory response. They are released into the bloodstream after maturation and differentiation from the bone marrow reservoir (5). The production of neutrophils has been estimated to range from 1 to $2 \times 10^{11}$ cells per day at steady state in a healthy adult. Neutrophils represent $50-70 \%$ of all circulating leucocytes in humans, while they account for $10-25 \%$ in mice (6). 


\section{Neutrophil Count to Lymphocyte Count Ratio (NLR)}

Circulating neutrophil counts are systematically monitored by oncologists during cancer management, owing to chemotherapyinduced neutropenia, which makes patients more vulnerable to life-threatening infections $(7,8)$. Availability of blood cell counts from retrospective analyses has led to numerous reviews and meta-analyses investigating the prognostic value of the neutrophil count (or preferably neutrophil-to-lymphocyte ratio, also called NLR) in both localized or metastatic contexts (912). Hence, over the past decade, literature on NLR has grown steadily. For instance, it is now well-acknowledged that NLR elevation is strongly associated with poor median progression-free survival (mPFS) and median overall survival (mOS) regardless of tumor type, stage of the disease or treatment (9). Interestingly, among metastatic patients, NLR has a prognostic value before chemotherapy and after subsequent lines of treatment in more advanced disease management (11). Optimal NLR cut-off values used to determine increased risk of mortality vary greatly (between 1.9 and 9.21) across studies (12). If we consider NLR as a continuous variable, each of its incremental increases in standard deviation is associated with a $35 \%$ increase in the risk of mortality. Moreover, patient follow-up duration influences NLR, as illustrated by the fact that the largest differences observed across patient prognostic groups occur within the first 12 months of follow-up (11). Beside confirming the baseline prognostic value of NLR, its early decrease following only one cycle of chemotherapy appears to be of good prognosis in multiple pathologies: (i) colorectal cancer (13, 14); (ii) mesothelioma; (iii) triple-negative breast cancer (15); (iv) docetaxel-treated patients bearing lung, prostate, head and neck or breast cancers (16); (v) advanced pancreatic adenocarcinoma; and (vi) in peripheral T-cell lymphomas (17).

Conversely, other retrospective studies did not confirm the predictive value of NLR across different randomized chemotherapy arms in colorectal cancer (18), or in advanced biliary tract carcinomas, in which low NLR values during chemotherapy were not associated with significant improvement in survival (only high NLR baseline values that decreased under chemotherapy predicted a significant better mOS) (19). NLR pretreatment values were not predictive of outcome in prostate cancer patients treated with docetaxel (20).

Variation in NLR values during targeted therapy seems to be an interesting biomarker of response in metastatic renal cell carcinoma patients (19). Templeton et al. reported a retrospective analysis of 1,199 patients treated with targeted therapies (bevacizumab, axitinib, sorafenib, sunitinib, temsirolimus) from the metastatic renal cell carcinoma database consortium and highlighted the predictive value of NLR variation between baseline (before targeted therapy commenced) and at 6 weeks ( \pm 2 weeks). They used a validation cohort of 4,350 patients from a prospective clinical trial. Compared to no change, a decrease in NLR exceeding $25 \%$ was associated with a significant improvement in the response rate, MPFS and mOS, while an increase was predictive of poor outcome. Of note, the highest response rates were observed in groups with low baseline NLR values that remained low at 6 weeks, though a good response rate was also reported in groups with an NLR superior to 3 which declined below 2.25 after the administration of targeted therapy (21). Similar observations were described in non-small cell lung carcinomas treated with gefitinib or erlotinib (22-24), advanced gastro-intestinal stromal tumors (25), advanced softtissue sarcoma treated with pazopanib (26), and hepatocellular carcinomas treated with sorafenib $(27,28)$.

The emergence of anti-CTLA4 and anti-PD(L)1 immunotherapies provides new hope in cancer management. However, due to an overall response rate below $40 \%(29,30)$ and to treatment costs, stratification of patients to identify the best candidate for immunotherapy has become a challenge. Readily available total blood count has enabled the evaluation of NLR in patients receiving immunotherapy, such as in advanced melanoma in which NLR in pretreated patients was identified as an independent marker of response (31-33), even when NLR was recorded during treatment (34). Similarly, in metastatic non-small cell lung carcinomas under anti-PD-1 therapy $(30,35)$, higher baseline NLR values were associated with a lower response rate (36). In patients with various advanced solid tumors candidates to phase I trials combining PD-1/PD-L1 inhibitors, a low NLR was correlated with response to treatment and improved OS, but not with increased immune toxicity (37).

Cancer-associated systemic inflammation often characterized by a high NLR, associated with a poor prognosis, was thought to occur only at late stages of tumorigenesis $(38,39)$. Evidence also suggests that NLR may increase at early-stage (stage I and stage II, separately) before treatment, and retains its poor prognostic significance in various cancer types including colon cancer (40), tongue cancer (41), breast cancer (42), and liver cancer (43). Early systemic modifications may therefore occur at early-stages of tumorigenesis.

Discrepancies across studies may be due to the level of heterogeneity of the populations studied (e.g., primary tumor, stage of disease, patient features: medical history or concomitant medication), limitations of retrospective reports, wide variation in NLR cut-off values, as well as in the dynamic assessment of NLR during treatment, and/or a lack of specificity of NLR (neutrophil count gathering immature neutrophils that might be released in the context of inflammation and expected circulating mature neutrophils). Interestingly, studies assessing the prognostic and/or predictive values of NLR in a wide variety of conditions (disease, stages, histology, treatment...) argue in favor of its utility. This correlation of NLR with clinical outcome suggests that changes in NLR may be linked with broader modifications beyond the tumor microenvironment. Hence, beyond being a relevant clinical biomarker, increase in NLR with disease progression highlights the importance of considering the systemic environment and not simply the tumor for a deeper understanding of biological mechanisms underlying cancer progression. It is possible that the tumor itself secretes factors into the bloodstream, which thereby act on bone marrow to skew hematopoiesis toward granulocytic lineages. Tumor may also release danger/damaged-associated molecules (DAMP) that might be a target for infiltrating neutrophils. Hence, the means by 
which an increase in NLR promotes cancer progression remains to be elucidated.

\section{T-Cell Suppressive Circulating Neutrophils}

Beyond their increase in the peripheral blood of cancer patients, which was associated with a poor prognosis, subsets of circulating neutrophils were reported to display tumorpromoting functions, inferring a causative role in cancer progression rather than just a consequence of the disease. The most-extensively described tumor-promoting function of circulating neutrophils remains their ability to suppress T-cell proliferation and/or activation in vitro. These T-cell suppressive neutrophils are classically termed granulocytic myeloid-derived suppressor cells (G-MDSCs) for both humans and mice. GMDSCs were documented to expand in tumor-bearing hosts compared to healthy subjects $(44,45)$. In cancer patients, GMDSCs are CD11b ${ }^{+} \mathrm{CD} 14^{-} \mathrm{CD} 6 \mathrm{~b}^{+} \mathrm{CD} 15^{\mathrm{hi}}$ expressing-cells that are enriched in the low-density neutrophils (LDNs) fraction present within the peripheral blood mononuclear cell (PBMCs) ring, unlike normal density neutrophils (NDNs), which are found in the granulocyte pellet of ficolled blood (46-49). In mice, G-MDSC correspond to $\mathrm{CD}_{11 \mathrm{~b}^{+}} \mathrm{Ly}^{\mathrm{int}} \mathrm{Ly}^{\mathrm{in}} \mathrm{G}^{\text {hi }}$-expressing cells present within the spleen or the tumor $(45,50,51)$, and only few studies refer mouse G-MDSCs to LDNs (44). Although LDNs are the best described neutrophil subset(s) in the blood of cancer patients, there is currently no clear LDN-specific biomarker(s). The scavenger receptor Lox1 was recently reported to be expressed by a subset of LDNs (48). Moreover, those LDNs contained both mature and immature neutrophils $(44,49)$. These findings suggest that LDNs remain a heterogeneous population of circulating neutrophils that need to be further characterized.

Recent studies conducted in human subjects, revealed new subsets of T-cell suppressive circulating neutrophils based on their stage of maturity. Activated mature neutrophils defined as CD11c ${ }^{\text {bright }}$ CD62L ${ }^{\text {dim }}$ CD11b $b^{\text {bright }}$ CD16 ${ }^{\text {bright }}$ cells in healthy volunteers challenged with LPS systemically (52) and CD66b ${ }^{+}$ CD11b ${ }^{\text {bright }}$ CD16 ${ }^{\text {bright }}$ mature LDNs in cancer patients (49) were reported to suppress T-cell proliferation. Both studies show that mature neutrophils inhibit interferon gamma production $(\operatorname{IFN} \gamma)$ by activated T-cells $(49,52)$. High level of $\mathrm{CD}_{66} \mathrm{~b}^{+}$ CD11b ${ }^{\text {bright }}$ CD16 ${ }^{\text {bright }}$ mature LDNs strongly correlated with adverse outcome in head and neck cancer (49). Interestingly, Evrard et al. demonstrated in a murine model of pancreatic cancer that the concentration of blood Ly6G ${ }^{\text {high }} \mathrm{CD} 101^{-}$ immature neutrophils was significantly greater in mice with a high tumor burden compared to the low tumor burden group, whereas this was not the case for mature neutrophils (53). In the same line, another group showed that the adoptive transfer of unipotent, committed human $\mathrm{CD} 6 \mathrm{~b}^{+} \mathrm{CD}^{+117^{+}}$ neutrophil progenitor $(\mathrm{hNeP})$ in immune deficient NSG-M3 mice accelerated osteosarcoma tumor growth compared with the transfer of committed monocyte progenitors (54). Surprisingly in this study, in vitro co-culture of either hNeP or mature bone marrow neutrophils with T-cells, activated the latter based on the upregulation of CD69, rather than inhibiting T-cell activation compared to control (54). The precise mechanisms by which immature circulating neutrophils contribute to tumor growth remain unknown.

The suppression of $\mathrm{T}$-cell proliferation by circulating neutrophils has been attributed to the release of different molecules. Reactive oxygen species (ROS) and Arginase 1 are the two most extensively described neutrophil-derived T-cell suppressive factors $(46-48,52,55)$. In humans, both factors require a CD18/Mac-1 immunological synapse between neutrophils and T-cells to display suppressive functions $(52,55)$. Circulating neutrophils appear to suppress T-cell proliferation via reversible cell cycle arrest rather than induction of apoptosis, as the addition of l-arginine or inhibition of arginase in neutrophil/T-cell co-cultures restored T-cell proliferation in G-CSF-treated healthy donors (55) and cancer patients, respectively (49).

\section{Circulating Tumor Cell-Escorting Neutrophils}

An emerging tumor-promoting function of circulating neutrophils has recently been unveiled. Neutrophils were shown to entrap circulating tumor cells (CTCs) at metastatic sites to facilitate their extravasation thus contributing to metastasis (56-60). Recent data showed that mouse neutrophils interacted with CTCs to promote their proliferation within the bloodstream and subsequently foster metastasis (61). In breast cancer patient blood, a high level of CTC-neutrophil clusters was associated with a higher risk of developing metastases (61).

Taken together, in addition to the NLR, there is a strong rationale for routinely monitoring CTC-neutrophil clusters with the aim of evaluating their prognostic impact and predictive value in cancer patients.

\section{PHENOTYPIC AND FUNCTIONAL HETEROGENEITY OF TUMOR-ASSOCIATED NEUTROPHILS (TANs)}

Neutrophils are able to infiltrate tumor tissue and are termed tumor-associated neutrophils (TANs). In mice, TANs express CD11b ${ }^{+}$Ly6C ${ }^{\text {int }}$ Ly6G ${ }^{\text {hi }}$, whereas in humans, they are identified as $\mathrm{CD} 11 \mathrm{~b}^{+} \mathrm{CD}^{-} 4^{-} \mathrm{CD} 6 \mathrm{~b}^{+} \mathrm{CD} 15^{\text {hi }}$ cells (50).

\section{Identification and Quantification of TANs in Cancer Patients}

The clinical relevance of evaluating pro- and anti-tumor functions of TANs is highly pertinent in cancer patients, since TAN infiltration was reported to predict either poor (62-66) or good prognosis (67-69). Conditions that differ between good and poor prognostic TANs will be discussed below. Although the methods of analysis of survival across studies were similar, identification of quantification methods of TANs infiltrating human tumors varied greatly. Hematoxylin \& Eosin (H\&E) staining remains a good approach to quantify TAN infiltration based on the unique segmented-nucleus morphology of neutrophils. Scanned-tumor slides stained with $\mathrm{H} \& \mathrm{E}$ are accessible from TCGA public database and have already been 
used for TAN quantification (70). However, this approach may under-estimate the potential infiltration of immature neutrophils since the banded-nucleus morphology of immature neutrophils is less distinguishable from other immune cells.

TAN infiltration can be also quantified through immunostaining, using antibodies against markers of neutrophils, such as CD66b and CD15. Neutrophils and eosinophils share numerous markers as they are closely related ontologically speaking, and very few studies took this cofounding effect into account. Evidence showed that CD66b is expressed at the same level between eosinophils and neutrophils in peripheral blood of patients with rheumatoid arthritis (71). For CD15 (Sialyl-Lewis X), although expressed on both eosinophils and neutrophils, data showed that it is 10-100 times higher on neutrophils than eosinophils (72). CD15 would therefore be more reliable to distinguish neutrophils from eosinophils, although the search for differentially expressed markers between these two cell types is strongly needed. Some studies also used myeloperoxidase (MPO), neutrophil elastase, CXCR2, or CD33 to identify TANs in human tumors. However, such markers are not specific to TANs and are shared by other immune cells $(45,73-76)$ or even tumor cells, such as CXCR2.

Bioinformatics approaches inferring the fractions of tumorinfiltrating immune cells from bulk tumor RNAseq data have recently emerged (77). The most classical approach for quantifying neutrophil infiltrate relies on single marker genes specific to neutrophils, such as CSF3R. Different groups have used this approach to classify tumors based on CSF3R expression $(78,79)$. Other approaches using multiple gene signatures have come to light. Although signatures slightly differ from one another study, algorithms processing these signatures vary greatly. For instance, single sample Gene Set Enrichment Analysis (ssGSEA) was recently used for the stratification of lung cancer patients based on the gene signature of a newly identified pro-tumor neutrophil population. CIBERSORT was used for quantifying neutrophil infiltrate in human tumor based on a signature composed of genes highly expressed in blood neutrophils compared to other blood leukocytes $(80,81)$.

\section{Pro-tumor TANs}

In both murine and human diseases, TANs are mostly described for their ability to promote tumor progression through different mechanisms, such as tumor cell proliferation. Mouse $\mathrm{Gr}^{+}$ myeloid cells secrete interleukin-1 receptor antagonist (IL-1RA), which were shown to antagonize the anti-tumor effects of cellular senescence in a murine model of $\mathrm{PTEN}^{-/-}$prostate cancer (82). Neutrophil elastase (NE), a protease secreted by neutrophils, accesses the endosomal compartment of tumor cells. There, it degrades the insulin receptor substrate 1 (IRS-1) which increases the interaction between PI3K and PDGFR, thereby promoting their proliferation in a LSL-K-ras model of murine lung adenocarcinoma and in human lung adenocarcinoma cell lines (83). Interestingly, the authors identified in human lung adenocarcinoma an inverse correlation between NE and IRS-1. Neutrophil-derived leukotrienes were also reported to selectively expand the subset of cancer cells that retained high tumorigenic potential (84). Accumulating evidence supports an important role for neutrophil extracellular traps (NETs), composed of DNA, that are associated with proteins such as NE and foster cancer progression. Mechanistically, neutrophils secrete HMGB1 during NETosis, thereby activating the TLR9 signaling pathways in cancer cells to promote their adhesion, proliferation, migration, and invasion (59). A more recent study reported that NETderived DNA could act as a scaffold for the neutrophil DNAassociated NE and MMP9 proteins during laminin-111 (matrix protein) remodeling which activated downstream integrin $\alpha 3 \beta 1$ signaling in disseminated, dormant cancer cells converting them into aggressive lung metastatic cancer cells (85). In addition to their role in tumor cell proliferation, NET-derived molecules such as Cathepsin G (CG) and NE were reported to promote invasion and migration of breast cancer cells (86). Indeed, NETs were observed by intravital imaging in vivo in the murine $4 \mathrm{~T} 1$-derived lung metastasis model. This finding was transferable to humans as they identified the deposition of NETs in triple-negative breast tumors. Recent evidence also implicates neutrophils in the induction of the epithelial to mesenchymal transition (EMT) by sustaining the expression of the EMT transcription factor Snail in cancer cells (87) or via the secretion of the tissue inhibitor of matrix metalloproteinase (TIMP-1) (88), which thereby facilitates metastatic progression. Evidence also suggest that neutrophils could favor angiogenesis and support tumor growth as neutrophil depletion was associated with a decreased number of developed vessels and a lower tumor weight (89). Pro-tumor TANs supporting angiogenesis, were reported to express high level of the proangiogenic factors VEGF and MMP9 in a mouse model of melanoma (89) and in liver tumorigenesis in zebrafish (90). Other groups support the fact that VEGF is highly expressed by pro-tumor TANs and may thus actively promote angiogenesis in mice $(91,92)$. Evidence in humans showed that fMLF-activated neutrophils induced sprouting of capillary-like structures via VEGF in an in vitro angiogenesis assay (93). Another group showed that human neutrophils could promote angiogenesis through NETs (94). In human gastric cancer, tumor cells were showed to make neutrophils produce MMP9, which significantly promoted angiogenic tube formation (95). Further studies in humans will be required to support the idea that proangiogenic neutrophils could promote tumor progression. In contrast, new evidence showed that TANs could foster cancer progression by altering angiogenesis instead, increasing hypoxia which in turn stabilizes the Snail EMT transcription factor, but also contributes to inhibit anti-tumor adaptive immunity (87). Moreover, evidence showed that neutrophils could impair angiogenesis by secreting antiangiogenic factors such as the isoform of VEGF-A, namely, VEGF-A $165 \mathrm{~b}(96,97)$.

TANs can also promote tumor progression by interacting with immune cells. TANs were mainly described for their ability to dampen T-cell-mediated anti-tumor immunity. In mice, depending on the tumor model, different TAN-derived soluble factors were reported to suppress proliferation and IFN $\gamma$ production of intra-tumor $\mathrm{CD}^{+}$T-cells, such as ROS (91) or nitric oxide (NO) produced by inducible nitric oxide synthase (iNOS) (98). The soluble enzyme arginase 1 derived from tumorinfiltrating myeloid cells was also suggested to mediate T-cell suppression (99). A recent single cell transcriptomic study across 
human and mouse lung tumor-infiltrating immune cells showed that arginase 1 was mostly expressed by TANs and tumorassociated macrophages (TAMs) $(100,101)$. Unlike human blood neutrophils, evidence in mice showed that TANs do not secrete arginase 1 but rather seem to retain it in the cytoplasm to deplete L-arginine intracellularly $(99,102)$. Other TAN-soluble factors were reported to induce T-cell apoptosis via the secretion of tumor necrosis factor alpha (TNFa) and NO (103). Lately, FasLigand (Fas-L) was shown to be expressed at the cell surface of TANs, leading to T-cell apoptosis in tumors resistant to T-cell based immunotherapies (104).

\section{Anti-tumor TANs}

Though largely believed to be pro-tumor, accumulating evidence suggests that TANs also play a role in anti-tumor immunity. Indeed, TANs appear to induce direct tumor cell apoptosis by secreting cytotoxic molecules such as $\operatorname{ROS}(91,105)$. Neutrophilderived extracellular DNA (NETs) were also reported to induce tumor cell death (106). Another intriguing anti-tumor property of TANs was recently identified. TANs were found to promote the detachment of tumor cells from the basement membrane at an early stage of mouse uterine carcinogenesis, a process known as tumor cell sloughing leading to tumor cell death (78). Accumulating evidence suggests that neutrophils may kill antibody-opsonized cancer cells via antibody-dependent cell cytotoxicity (ADCC), which involves Fc receptors (107110). Recently, an original mechanism of ADCC, a process termed trogoptosis, was described (111). Indeed, neutrophils establish a synapse with cancer cells, which strongly depends on neutrophil CD11b/CD18 integrins, allowing neutrophils to ingest a fraction of the antibody-opsonized plasma membrane of cancer cells (trogocytosis). A mechanical disruption of the plasma membrane concomitantly occurs, leading to a lytic/necrotic form of cell death. In sharp contrast with the other ADCC-related cytotoxic mechanisms mostly described in NK cells, trogoptosis is independent of granule exocytosis and of the phagocyte NADPH oxidase. Lastly and more importantly, intravital imaging demonstrated that trogoptosis occurs in vivo in mice (111).

Another anti-tumor role for TANs in mice and humans was uncovered with their implication in the recruitment and activation of intra-tumor $\mathrm{CD} 4^{+}$and cytotoxic $\mathrm{CD} 8^{+} \mathrm{T}$ cells $(91$, 112). A recent study conducted in mice genetically deficient for Tollip, an innate immunity signaling adaptor molecule inhibiting the TLR signaling pathway and potentially other pathways, led to the upregulation of STAT5 and STAT1. This in turn upregulated the co-stimulatory CD80 and downregulated the immune checkpoint PD-L1, specifically in TANs (112). These molecules are both important for T-cell proliferation, IFN $\gamma$ and granzyme B production. Adoptive transfer of Tollip-deficient neutrophils slowed down colitis-associated cancer progression, thus highlighting a role for Tollip in modulating TAN-mediated cancer immune surveillance (112). In human colorectal cancer, $\mathrm{CD} 6 \mathrm{~b}^{+}$TANs stimulate proliferation and induce secretion of IFN $\gamma$ from $\mathrm{CD}^{+} \mathrm{T}$ cells in vitro (113). Moreover, $\mathrm{CD}^{+} 6 \mathrm{~b}^{+}$ TANs frequently co-localize with $\mathrm{CD} 8^{+} \mathrm{T}$-cells in tumor tissue (113). At an early stage of human lung tumors, TANs were put forward as T-cell antigen presenting cells (APCs), with a high capacity to stimulate T-cell proliferation and IFN $\gamma$ production $(114,115)$. A recent study conducted in a murine sarcoma model showed that TANs acting in concert with macrophages, were essential for unconventional $\alpha \beta \mathrm{T}$ cell type 1 polarization to display anti-tumor potential in vivo by secreting IFN $\gamma$ (79).

\section{TAN Subsets}

With such functional heterogeneity of neutrophils, one could hypothesize that different subsets of TANs may be involved. Previous studies on blood and bone marrow neutrophils led to the discovery of new cell-surface markers to distinguish mature from immature neutrophils. Recent evidence showed that both mature and immature neutrophils can infiltrate mouse and human tumors, and were either reported to promote or prevent tumorigenesis $(53,54,115,116)$. Density could also discriminate a subset of blood neutrophils, known as LDNs, isolated by density gradient centrifugation. This method is suitable for blood samples, though its application to tumor samples may not be possible, which remains to be investigated. The search for cell-surface biomarkers of LDNs is thus needed to evaluate the relevance of LDNs in tumors. The previously identified Lox1 marker specific to a subset of LDNs was validated in situ in melanoma, colon, head and neck, and non-small cell lung cancer (48). But it remains to be verified if lox 1 is not intracellularly expressed by all neutrophils. Characterization of TAN subsets based on cell-surface antigens remains limited to a dozen markers, making the comparison of neutrophil subsets across tissues difficult. Therefore, it remains therefore unclear whether immature blood neutrophils are identical to immature TANs. To further characterize subsets of TANs, transcriptomic profiling of neutrophils is strongly required. A recent single cell transcriptomic study performed in lung cancer patients showed distinct subsets of TANs and blood neutrophils with few overlaps between tissues (101). Whether such a difference can be attributed to differences in processing or isolation of neutrophils between tumor tissues and blood, or whether it is a true biological difference between tissues, remains to be addressed in future investigations. This study demonstrated that different subsets of TANs may co-exist in the same tumor, some being preferentially enriched, while certain TAN subsets seem to be found exclusively either in healthy or tumor tissue (101). The authors also sequenced at the single-cell level TANs from murine lung tumors (101). Unbiased comparison between mouse and human TANs showed conserved subsets allowing scientists to test the functional relevance of distinct subsets in tumor progression and response to therapies in murine models, and eventually apply finding to cancer patients. The work of Zilionis et al. unveiled TAN heterogeneity in the lung tumor context and it remains to be determined whether the same applies other tumor types. Another major ongoing issue is TAN ontogeny, and future investigations are needed to decipher whether TAN subsets correspond to transitional cell states referring to the concept of polarization or whether they are terminally-differentiated distinct cell types, and if TANs present in the tumor microenvironment are derived from circulating G-MDSCs. 
A

Prognostic impact of TANs at early and late-stage of tumorigenesis

\begin{tabular}{|c|c|c|c|c|c|c|}
\hline Tumor stage & Cancer Type & $\begin{array}{c}\text { In situ localization of } \\
\text { neutrophils }\end{array}$ & Neutrophil markers & Prognostic impact & OS/DFS/CSS & References \\
\hline \multirow{3}{*}{ Stage I-II } & CRC & Tumor front & CD66b & Improved & css & Wikberg ML et al. $2017^{(117)}$ \\
\hline & SKCM & Intratumoral & CD66b & Worsened & OS / DFS / CSS & Jensen TO et al. $2012^{(119)}$ \\
\hline & Cervical SCC & Peritumoral & CD66b & Worsened & DFS & Carus A et al. $2013^{(120)}$ \\
\hline \multirow{2}{*}{ Stage II } & \multirow{2}{*}{ CRC } & Intratumoral & $\begin{array}{c}\text { H\&E (morphology) and } \\
\text { Arginase }\end{array}$ & Improved & os & Berry RS et al. $2017^{(118)}$ \\
\hline & & Intratumoral & CD66b & Worsened & OS & Rao H-L et al. $2012{ }^{(63)}$ \\
\hline Stage III & CRC & Intratumoral & CD66b & Worsened & Os & Rao H-L et al. $2012^{(63)}$ \\
\hline Stage III-IV & HNSCC & Intratumoral & CD66b & Worsened & os & Trellakis S et al. $2010^{(64)}$ \\
\hline
\end{tabular}

B

Ex-vivo functional analysis of TANs at early and late-stage of tumorigenesis

\begin{tabular}{|c|c|c|c|c|}
\hline Tumor stage & Cancer Type & Ex-vivo functionality & Neutrophil markers & References \\
\hline Stage I-II & NSCLC & $\begin{array}{c}\text { TANs enhance T-cell proliferation and } \\
\text { secretion of IFNy }\end{array}$ & $\begin{array}{c}\text { CD66b, CD15, CD14, } \\
\text { OX40L, 4-1BBL, CD54, } \\
\text { CD86, MHC-II }\end{array}$ & $\begin{array}{c}\text { Eruslanov EB et al. 2014 } \\
\text { Singhal S et al. 2016 }\end{array}$ \\
\hline Stage III-IV & Gastric cancer & $\begin{array}{c}\text { TANs suppress T-cell proliferation and } \\
\text { production of IFNy }\end{array}$ & CD66b, CD54, PD-L1 & Wang T-T et al. 2017 \\
\hline Unknown? & CRC & $\begin{array}{c}\text { TANs enhance T-cell activation (CD69) } \\
\text { and secretion of IFNy }\end{array}$ & CD66b, CD54 & Governa V et al. 2017 \\
\hline (113) \\
\hline
\end{tabular}

FIGURE 1 | (A) This figure reviews studies supporting the improved or worsened prognostic impact of TANs in situ at early (stage I and stage II; stage II alone) and late-stage (stage III; stage III and IV) of tumorigenesis across different cancer types. Quantification neutrophils based on a particular location in situ was precised (intratumoral, tumor front, and peritumoral). Neutrophil markers used for identification of neutrophils in situ by immunostaining were either CD66b or Arginase. Others identified neutrophils in situ based on their morphology through Hematoxylin and Eosin (H\&E) staining. Patient prognostic impact was assessed based on overall survival (OS), disease-free survival (DFS), and cancer specific survival (CSS). Light gray background refers to early-stage tumors whereas dark gray background points out late-stage tumors. Abbreviations were used for the cancer type column: CRC, Colorectal cancer; SKCM, Skin Cutaneous Melanoma; Cervical SCC, Cervical squamous cell carcinoma; HNSCC, Head and Neck squamous cell carcinoma. (B) This figure covers studies ex-vivo functional analysis supporting the anti-tumor or pro-tumor role of neutrophils in early (stage I and II) or late-stage (stage III and IV) of tumorigenesis in various cancer types. This figure includes markers expressed at protein level by anti-tumor or pro-tumor neutrophils. Light gray background refers to early-stage tumors whereas dark gray background points out late-stage tumors. White background was set for unknown tumor stage. Abbreviations were used for the cancer type column: NSCLC, Non-small-cell lung carcinoma; CRC,

Colorectal cancer.

\section{TANs in Early vs. Later-Stage Tumors}

Evidence in mice supports this idea that the pro- and anti-tumor role of neutrophils may be strongly linked to tumor stage. Mice with genetic deficiency of GCSF-R displayed an accelerated tumor initiation at early-stage in a spontaneous murine model of uterine carcinogenesis (78) and 3-methylcholanthrene (3-MCA)induced sarcomagenesis (79), attesting an anti-tumor role at early-stage of tumorigenesis. In contrast, antibody-mediated neutrophil depletion in established tumors at late-stage, led to decreased tumor growth, supporting a pro-tumor role at late-stage $(84,98)$.

In humans, evidence for pro- and anti-tumor functions of TANs arose from retrospective studies assessing the prognostic value of tumors highly infiltrated with neutrophils (Figure 1A). The prognostic impact of TANs remains controversial as they are associated with either a better or worse outcome. Such discrepancies can be explained by the cancer type, the in situ location (peritumoral, intratumoral, or stromal) of neutrophils but also by differences in staining methods such as haematoxylin/eosin (HE), neutrophil elastase (NE), Arginase, MPO, CD66b, or CD15 surface markers. New evidence suggest that the tumor stage may also explain such differences (Figure 1A). In colorectal cancer (CRC) patients, the good prognostic impact of TANs is described in earlystage colorectal tumors, especially stage I-II tumors combined (117), or stage II alone (118). Only one study in CRC patients showed that a high intratumoral infiltration of TANs was associated with a worse overall survival (63). The worse prognostic impact of TANs in early-stage tumors was reported in melanoma (119) and cervical squamous cell carcinoma (120). In late-stage tumors, especially in CRC and head and neck squamous cell carcinoma, the prognostic impact of TANs is generally poor $(63,64)$. To our knowledge, there is no study reporting a good prognostic significance of TANs in late-stage tumors.

Other evidence supporting the link between anti- or protumor function of TANs with the tumor stage came from ex vivo functional analysis of TANs (Figure 1B). In gastric cancer patients, TANs isolated from fresh tumors co-cultured with purified autologous peripheral blood $\mathrm{CD}^{+} \mathrm{T}$ cells displayed higher immunosuppressive function than neutrophils from healthy adjacent tissue (121). In this study, T-cell suppression is partially explained by $\mathrm{PD}-\mathrm{L} 1$ expression on TANs since PD-L1 blocking antibodies reverse T-cell proliferation (121). Interestingly, the authors showed that $\mathrm{PD}-\mathrm{L}^{+}$TANs were 
significantly higher in advanced (stages III-IV) vs. earlystage tumors (stage I-II), suggesting that pro-tumor PD$\mathrm{L}^{+}$neutrophils only emerge at a later-stage of gastric tumorigenesis. Further investigations will be needed to confirm the predominance of pro-tumor TANs in late-stage gastric tumors compared to early-stage tumors. In sharp contrast, in lung cancer patients, TANs, not peripheral blood neutrophils, from early-stage tumors (stages I-II), were reported to enhance the proliferation of autologous T-cells stimulated with antiCD3/CD28 antibodies $(114,115)$, suggesting an anti-tumoral function. Nevertheless, the improved prognostic impact of TANs in early-stage lung tumors remains to be assessed. In CRC, coculture of human TANs from colorectal tumors with autologous CD8 T-cells resulted in an increased expression of the CD69 T cell activation marker and a higher release of IFN $\gamma$ in culture supernatant (113). However, it remains to be determined if these CD8 T-cell-stimulatory TANs are enriched in early-stage colorectal tumors as compared to late-stage tumors. In line with the CD8 T-stimulatory anti-tumor role of neutrophils in CRC, the majority of studies on favorable outcome of TANs in earlystage tumors are in CRC (Figure 1A). Thus, it cannot be excluded that not tumor stage but rather tumor type (and possibly involvement of microbiota), is responsible for this observation, in CRC. Human undifferentiated pleomorphic sarcomas (UPS) recently emerged as another type of cancer in which dense neutrophil infiltrate was found to be associated with better prognosis, regardless of tumor stage (79). The search for cancer type-specific features, especially in CRC and UPS will be the object of future investigations to potentially identify new factors important for the stimulation of anti-tumor neutrophils.

\section{ORIGIN OF PRO- AND ANTI-TUMOR NEUTROPHILS}

Having reviewed the heterogeneity of pro- and anti-tumor neutrophils in cancer, it is necessary to discuss their origin.

\section{Neutrophil Activation}

The anti- or pro-tumor properties of neutrophils often result from the activation of neutrophils. Neutrophil-derived NETs were previously described to have both pro (85) and antitumor properties (106). In vitro, NETs can be generated upon acute stimulation of neutrophils with lipopolysaccharide (LPS), Phorbol 12-myristate 13-acetate (PMA), N-Formylmethionylleucyl-phenylalanine (fMLF formerly termed fMLP) (83, 106, 122) in both human and mice. Whereas, PMA or AMLF was sufficient to induce NETs (122). Mechanistically, LPS-stimulated platelets via TLR4 which in turn led to the activation of neutrophils thus leading to NETosis. Other platelet activators such as thrombin were found to be equally efficient in producing NETs in presence of platelets (123). The mechanism by which activated-platelets promote NETosis is still not clear and will require further investigations. Cancer cell-derived soluble molecules such as G-CSF were also suggested to induce NETs (86). The engagement of the Fc-alpha receptor (FcaRI/CD89) (124) or Fc-gamma receptor (Fc $\gamma$ RIIIB/CD16) (125) was also reported to induce NETs. Neutrophil-derived NET formation is not restricted to in vitro stimulation, as it can be reproduced in mouse blood following acute systemic sepsis (58) and in mouse lung tumor after chronic nasal instillation of LPS (84). Neutrophils were also described to display T-cell suppressive functions. Both mouse and human neutrophils acutely stimulated by high doses of IFN $\gamma$, up-regulate T-cell suppressing ligands such as PD-L1 which in turn decrease T-cell proliferation (115, 126). The acute induction of endoplasmic reticulum (ER) stress upon thapsigargin (THG) stimulation in human circulating neutrophils was reported to convert these cells into T-cell suppressive G-MDSCs, notably by inhibiting T-cell proliferation (48). Interestingly, in contrast to THG treatment, fMLF and PMA-stimulated neutrophils did not block T-cell proliferation. Instead, PMA-stimulated neutrophils appear to have T-cell suppressive effects by inhibiting the production of T-cell derived IFN $\gamma$ (127). Activation of the complement receptor 3 (MAC$1 / \mathrm{CD} 11 \mathrm{~b})$ signaling pathway also seems important for the induction of T-cell suppressive neutrophils (128).

The engagement of Fc-receptors on neutrophils constitutes another way of activating neutrophils and was reported to lead to killing of antibody-opsonized cancer cells by ADCC in vitro $(109,111)$ and in vivo (111). Interestingly, neutrophils were shown to induced ADCC more efficiently with IgA antibodies in comparison to IgG antibodies $(107,108,110)$. Using hFcaRI transgenic mice, IgA anti-EGFR antibodies were proven to mediate tumor cell killing in vivo (129). Recent evidences support the idea that ADCC could occur in vivo as revealed by intravital imaging (111). Taken together, direct acute or chronic stimulation of neutrophils seems to be sufficient to transform naïve neutrophils into pro- or anti-tumor neutrophils. Collectively, neutrophil activation may in turn lead to a variety of pro- and anti-tumor function depending on type, dose of activator, time of stimulation, and tumor model.

\section{Neutrophil Differentiation}

By definition, differentiation implies the development of a given progenitor toward several different mature cells with distinct cell fates. Depending on environmental cues, neutrophil progenitors were reported to differentiate into different subsets of neutrophils with either pro- or anti-tumor functions $(115,130,131)$.

Mounting evidence indicates that IFN $\gamma$ and GM-CSF, two cytokines abundantly present in early-stage human lung tumors, are essential for the differentiation of $\mathrm{CD} 11 \mathrm{~b}{ }^{+} \mathrm{CD} 15^{\mathrm{hi}} \mathrm{CD} 66 \mathrm{~b}^{+}$ $\mathrm{CD} 16^{\text {int/low }} \mathrm{CD}^{-} 0^{-}$bone marrow neutrophil progenitors into anti-tumor $\mathrm{CD}^{+} 0^{+}$mature $\mathrm{MHC}-\mathrm{II}^{+}$antigen presenting neutrophils, known as "APC-like hybrid neutrophils" (114, 115). Surprisingly, besides expressing APC markers, this TAN subset was shown to express markers of monocytes such as CD14. Both IFN $\gamma$ and GM-CSF downregulate the expression of the Ikaros transcription factor, known to negatively regulate the development of monocytes/macrophages which may explain the acquisition of CD14 $(132,133)$. Interestingly, the Ikaros inhibitor, lenalidomide, synergizes with IFN $\gamma$ and GM-CSF to generate APC-like hybrid neutrophils, but is unable to do so alone, suggesting that other pathways activated by IFN $\gamma$ and GM-CSF are necessary for this differentiation, though 
these latter remain to be unraveled. Moreover, the authors showed that APC-like hybrid neutrophils could also be generated from $\mathrm{CD} 11 \mathrm{~b}^{+} \mathrm{CD} 15^{\text {hi }} \mathrm{CD} 66 \mathrm{~b}^{+} \mathrm{CD} 16^{\text {int } / \text { low }} \mathrm{CD} 10^{-}$low-density immature peripheral blood neutrophils from G-CSF-treated healthy donors (115). Since neutrophil progenitors may also circulate in the bloodstream of cancer patients $(54,55)$, it is therefore possible that circulating neutrophil progenitors are recruited at the tumor site to differentiate into APC-like hybrid TANs. Neutrophil progenitors used for the generation of APClike hybrid neutrophils were isolated from bone marrow of cancer patients or from peripheral blood of G-CSF-treated healthy donors (115). It therefore remains unclear whether systemic priming of neutrophil progenitors by tumor-secreted factors, including G-CSF is a prerequisite for their differentiation into APC-like hybrid neutrophils upon exposure to IFN $\gamma$ and GMCSF at tumor site.

Recent evidence supports the concept that neutrophils need to be primed systemically to differentiate into pro-tumor TANs. A recent study in mice showed that the differentiation of bone marrow-derived hematopoietic stem and progenitor cells (HSPCs) into pro-tumor SiglecF ${ }^{+}$TANs (130) required bone marrow osteoblasts. Indeed, in vivo cell fate mapping experiments showed that the differentiation of SiglecF ${ }^{+}$TANs from bone marrow c-Kit ${ }^{+}$HSPCs was abrogated in osteoblastdeficient mice, suggesting that the bone marrow is essential for the priming of pro-tumor SiglecF ${ }^{+}$TANs. Extra-medullary tissues such as the spleen were also necessary for the differentiation of HSPCs into T-cell suppressive TANs (131). Splenectomy was indeed reported to blunt T-cell suppressive functions of TANs and synergistically enhanced anti-PD-L1 therapeutic efficacy. Mechanistically, the spleen of tumor-bearing mice mediates the recruitment of circulating HSPCs through CCL2/CCR2 axis, which then differentiate into T-cell suppressive G-MDSC via splenic stromal-derived GM-CSF. This is in line with previous studies showing that T-cell suppressive G-MDSCs expand in the spleen, which is most often characterized by splenomegaly (134). Collectively, although evidence in mice suggests that the systemic environment such as the bone marrow and the spleen are necessary for the differentiation of neutrophil progenitors to pro-tumor TANs, it is still unclear whether this systemic priming is sufficient for differentiation to pro-tumor TANs or whether it requires additional cues at tumor site for example, remains unknown.

In humans, systemic priming appears to be necessary for the generation of T-cell suppressive neutrophils. Indeed, a study recently showed that mature $\mathrm{CD}^{+} 0^{+}$neutrophils from G-CSF-treated healthy donors display T-cell suppressive properties ex vivo, whereas those from untreated healthy donors did not. Interestingly, $\mathrm{CD}^{+} 0^{+}$neutrophils from untreated healthy donors treated with G-CSF in vitro did not display any suppressive activities (55). This suggests that, in humans, G-CSF alone is not sufficient to induce T-cell properties on neutrophils and thus requires other probably systemic cues.

The tumor may also alter the differentiation of neutrophils for its own benefit, by interfering with their maturation toward an anti-tumor phenotype. This concept was initially demonstrated for tumor-infiltrating monocytes. Here, the maturation into antitumor macrophages was blocked leading to promotion of tumor growth in a murine model of hepatocellular carcinoma (HCC) (135). Accumulating evidences in humans and mice suggest that immature neutrophils infiltrate tumors, retain their immature phenotype at the tumor site and are correlated with a higher tumor burden $(53,54,98,116)$. Aside from the hypothesis that interfering with neutrophil maturation could alter their differentiation into anti-tumor neutrophils, this data suggest that at least some neutrophil progenitors may also have a naturally occurring T-cell suppressive function per se. Indeed, immature bone marrow neutrophils from healthy donors were reported to display spontaneous T-cell suppressive properties, although this remains to be confirmed in further studies (54). The biological characterization of immature TANs and their clinical implication should be the subject of future investigations.

\section{NEUTROPHIL-BASED THERAPEUTIC STRATEGIES}

Since neutrophils display various tumor-promoting functions and are predictive of poor patient OS, one potential therapeutic strategy could be the targeting of neutrophils in vivo. Preclinical studies in the mouse have already reported therapeutic effects of neutrophil depletion using the specific neutrophildepleting antibody, anti-Ly6G (84, 87, 98, 104). Here, we review the different therapeutic strategies that aimed at targeting neutrophils in cancer (Figure 2).

\section{Prevention of Neutrophil Exit From Bone Marrow and Entry to Tumor Tissue G-CSF/L-17 Axis Modulation}

A number of studies in mice have suggested modulating the level of G-CSF to prevent the expansion of pro-tumor neutrophils. In mice, ablation of G-CSF with anti-G-CSF antibodies was also shown to prevent neutrophil accumulation in bloodstream (61, 98, 136), whereas overexpression of G-CSF induced the expansion of circulating neutrophils and increased metastasis $(61,136,137)$. Although G-CSF is being used to stimulate the production of neutrophils in patients who suffer from chemotherapy-induced neutropenia (138), it remains unclear if endogenous G-CSF is responsible for neutrophilia observed in cancer patients. Few studies reported a higher level of serum GCSF in patients with pancreatic cancer (139), colorectal cancer (140) and non-small cell lung cancer (141), as compared with healthy subjects. None of these studies showed an association between high serum G-CSF concentration and neutrophilia. Only few case report studies reported a link between a high endogenous serum G-CSF level and an increase of white blood cell count consisted primarily of neutrophils (142-144). Taken together, the role of endogenous serum G-CSF as a dominant driver of neutrophilia in cancer patients remains weak. Furthermore, endogenous serum G-CSF levels has not been linked to poorer prognosis to date. Noteworthy, exogenous therapeutic G-CSF does not seem either to worsen survival of cancer patients treated with chemotherapy $(145,146)$. 


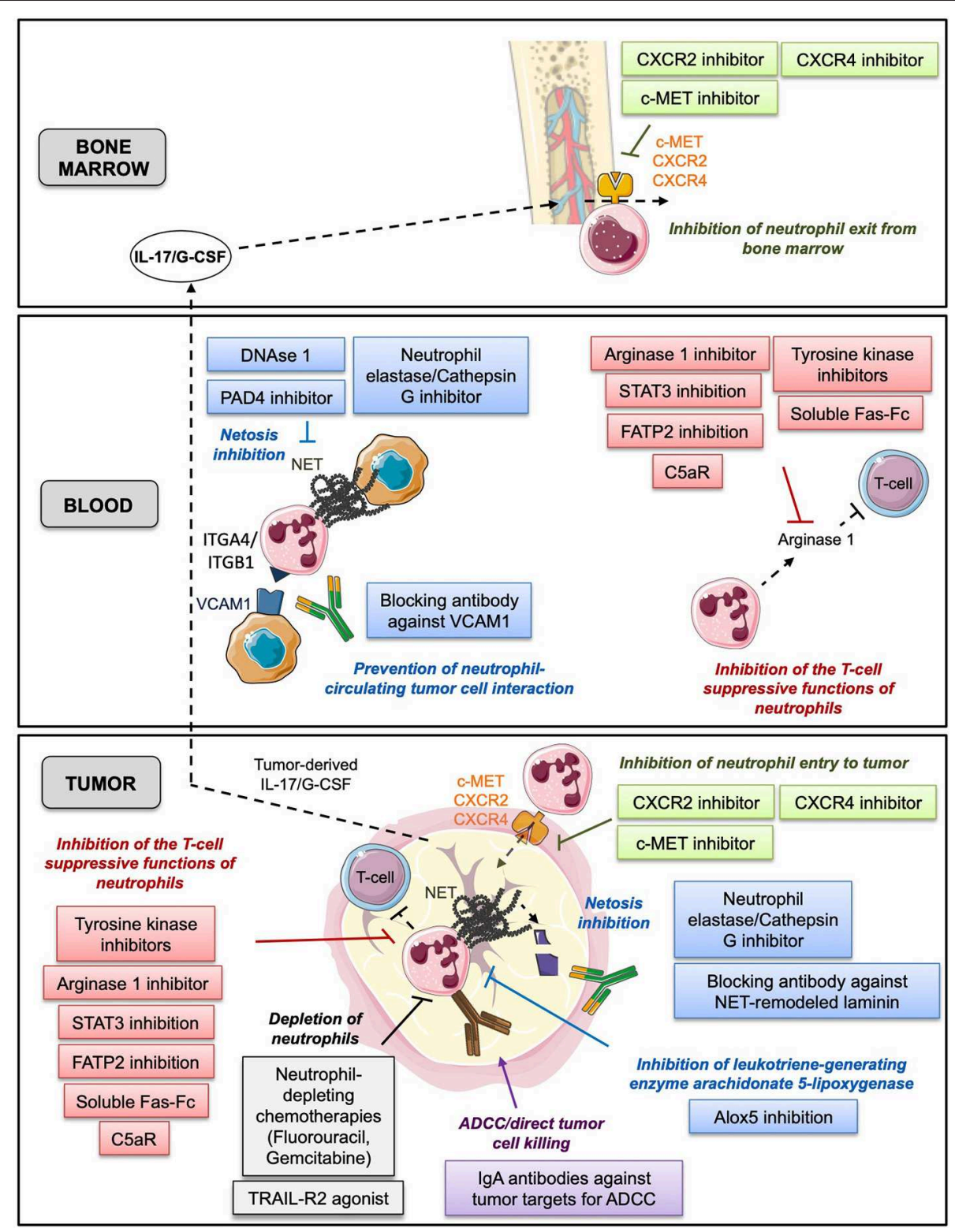

FIGURE 2 | This figure summarizes the different neutrophil-based therapeutic strategies with various mechanisms of action described in bone marrow, blood and tumor. In green: prevention of neutrophil exit from bone marrow and entry to tumor tissue. In gray: depletion of neutrophils. In red: inhibition of the T-cell suppressive functions of neutrophils. In blue: prevention of neutrophil capacity to foster tumor cell proliferation and migration. In purple: promotion of the anti-tumor functions of neutrophils.

Interleukin-17 (IL-17) recently emerged as an upstream regulator of G-CSF and subsequently of neutrophil production in vivo (98, $147,148)$. In a murine model of lung metastasis, neutralization of IL-17 significantly reduced the level of G-CSF and prevented the systemic expansion of blood neutrophils. Interestingly, studies report an increase of IL-17 in the blood of patients with liver cancer (149), non-small cell lung cancer (148, 150, 151). High level of serum IL-17 was even associated with a worse prognostic for non-small cell lung cancer patients $(150,151)$. Nevertheless, the link between level of serum IL-17 and neutrophilia remains to be investigated in future studies.

\section{CXCR2/CXCR4 Inhibition}

CXCR2 is known to be important for neutrophil migration, controlling their egress from the bone marrow to the bloodstream and their recruitment to sites of inflammation (152-155). Neutrophil acquire CXCR2 to exit bone marrow $(153,154)$. The genetic or pharmacological inhibition of CXCR2 was reported to decrease primary lung tumor growth $(156,157)$ and suppress pancreatic cancer metastasis in mice (157). In both studies, specific depletion of $\mathrm{Ly}_{6 \mathrm{G}}{ }^{+}$neutrophils recapitulated the therapeutic effect of CXCR2 inhibition. CXCR2 inhibition was followed by an increase in circulating neutrophils due to their 
inability to home $(156,157)$. Although some evidence indicates that CXCR2 inhibition could prevent recruitment of CD11 $\mathrm{b}^{+}$ $\mathrm{Gr}^{+}$myeloid cells in $\mathrm{PTEN}^{-/-}$prostate tumors (82), it remains unclear whether $\mathrm{Ly}_{6 \mathrm{G}}{ }^{+}$neutrophil infiltration at the tumor site is impaired. Since therapeutic effects of CXCR2 inhibition may also be explained by its direct action on tumor cells (158160 ), future studies are needed to determine the contribution of neutrophils to CXCR2 inhibition-related therapeutic effects. This would provide a rationale for using CXCR2 as a potent inhibitor of neutrophil recruitment.

CXCR4 was reported to act antagonistically with CXCR2 for bone marrow exit of neutrophils $(153,154,161)$. Neutrophils lose CXCR4 to egress from the bone marrow to be released in the circulation $(154,161)$. However, CXCR4 acquisition seems important for infiltration of neutrophils into the tumor, at least in a preclinical model of colorectal cancer. Hence, blockade of CXCR4 using the FDA-approved agent Plerixafor (AMD3100) inhibited anti-VEGFR2 therapy-induced tumor infiltration of neutrophils and Ly6C ${ }^{\text {low }}$ monocytes (162). Increasing number of studies report the therapeutic effects of inhibiting CXCL12/CXCR4 axis by targeting cancer and stromal cells from the tumor microenvironment (163). Very few studies looked at the effects of CXCR4 blockade on tumor-infiltrating immunosuppressive myeloid cells including neutrophils and it remains the object of future investigations. Taken together CXCR4 inhibition appears to be an interesting strategy when used in combination with chemotherapy. This by preventing neutrophils from entering into the tumor while mobilizing bone marrow neutrophils which could compensate chemotherapy-induced neutropenia classically managed by GCSF injection. Hence, several pre-clinical studies showed the additive therapeutic effects of CXCR4 inhibition with chemotherapies (164-166).

\section{C-Met Inhibition}

Capmatinib, an inhibitor of the tyrosine-protein kinase MET (c-MET), was first developed to treat cancer patients with alterations affecting the c-MET pathway in cancer cells due to activating mutations, overexpression, gene amplification, and translocations (167). Interestingly, capmatinib potentiated therapeutic effects of adoptive T-cell transfer and checkpoint immunotherapies in several mouse models of cancer by preventing the reactive mobilization and recruitment of T-cell suppressive neutrophils to tumors and draining lymph nodes (126). Importantly, the therapeutic effect was restricted to c-MET signaling in neutrophils as the genetic ablation of c-MET kinase activity specifically in neutrophils could reproduce the same effect. Moreover, tumor cell lines were insensitive to capmatinib in vitro and in vivo, excluding any tumor cell-intrinsic c-MET dependency in this study. Another study showed that capmatinib also prevented the recruitment of anti-tumor TANs (168) in different tumor models. Whereas, cancer cell lines knocked down for c-MET had a slower tumor growth rate in mice, the addition of capmatinib countered the therapeutic effect of cMET knockdown, suggesting that TME-expressing c-MET were involved in the anti-tumor response. TANs appeared to express c-MET which is essential for their recruitment at the tumor site and thereby activation of their anti-tumor function. These studies therefore argue in favor of evaluating the expression of c-MET in both tumor cells and neutrophils in cancer patients who receive capmatinib treatment.

\section{Depletion of Neutrophils TRAIL-R2 Agonist Antibody}

An agonistic antibody of the TNF-Related Apoptosis-Inducing Ligand Receptor 2, known as TRAIL-R2, was proposed to induce cell death of mouse G-MDSC in vitro and to potentiate the effect of CTLA-4 immune checkpoint blockade in vivo. A recent firstin human clinical trial evaluated the clinical impact of targeting TRAIL-R2. In cancer patients with elevated levels of LDNs before treatment, the TRAIL-R2 agonist antibody selectively depleted LDNs without impacting the number of other peripheral blood myeloid and lymphoid cells, nor showing dose-limiting toxicities (169). However, the selective depletion of LDNs could not be sustained up to 28 days after the start of the treatment. Due to short-term treatment and the small number of patients in the cohort, further studies will be needed to conclude on the selective depletion of LDNs upon TRAIL-R2 agonist antibody treatment.

\section{Chemotherapies}

Aside from their potential cytotoxic effects on tumor cells, studies in mice revealed that some chemotherapies may also have side effects on immune cells, including neutrophils. Indeed, fluorouracil (5FU) was reported to have anti-tumor effects in vivo in mice and was associated with depletion of splenic and tumor G-MDSCs and monocytic MDSCs (M-MDSCs) (170). In this study, the therapeutic efficacy of $5 \mathrm{FU}$ regarding tumor immunity was suggested to most likely be restricted to M-MDSC-depletion since 5FU did not deplete any other immune cell type, nor induce immunogenic tumor cell death. Nevertheless, the same group reported several years later that $5 \mathrm{FU}$ and Gemcitabine could also drive M-MDSC-derived IL-1b secretion that induce the release of CD4 T-cell-derived IL-17, which in turn blunts the anticancer efficacy of these chemotherapeutic agents. However, gemcitabine and $5 \mathrm{FU}$ were shown to exert higher anti-tumor effects when tumors were established in $\mathrm{Nlrp}^{-/-}$or Casp $1^{-/-}$ mice or wild-type mice treated with the IL-1 receptor antagonist (IL-1Ra) (171). Therefore, the depleting effect of 5FU on MDSCs, including G-MDSCs, still remains a matter of debate and requires further investigation.

Taken together, studies aiming at evaluating the neutrophildepleting effects of already-approved therapies remain contrasted. These discrepancies are likely due to differences in doses, timing of administration, location of neutrophil sampling, time of neutrophils detection, as well as mouse and tumor models $(172,173)$. Future investigations should therefore take into account these parameters to identify in which settings these potential neutrophil-depleting therapies could be the most beneficial. Since neutrophils are constantly monitored during cancer treatment to prevent neutropenia and therefore avoid opportunistic infections, depletion of neutrophils must be restricted to the tumor site (TANs), or only to subsets of neutrophils with tumor-promoting function. To support the rationale that currently-used chemotherapies may offer 
additional therapeutic effects by targeting TANs, it will be important to determine whether a higher infiltration of TANs prior to the administration of neutrophil-depleting treatments is associated with a better survival. Interestingly, evidence in stage III colorectal cancer patients all treated with 5FU after surgical removal, showed that a high density of intratumoral TANs before treatment was associated with a longer disease-free survival (68). TAN infiltrate may therefore help identify patients who will likely benefit from 5FU chemotherapy.

\section{Inhibition of the T-Cell Suppressive Functions of Neutrophils Arginase 1 Inhibitor}

L-arginine is an important amino acid that serves as a building block for protein synthesis and as a precursor for multiple intra-cellular metabolites (174). L-arginine is known to be particularly important for T-cell proliferation and survival (175). Moreover, increased intracellular L-arginine in T-cells was shown to favor their differentiation to central memory-like T-cells with enhanced anti-tumor properties (176). L-arginine is mainly catabolized by arginase 1, which is secreted by subsets of myeloid cells, including neutrophils under specific conditions in humans $(46,55)$. Several reports demonstrated in vitro that neutrophilderived arginase 1 suppresses T-cell proliferation (55), which was rescued by the addition of an arginase 1 inhibitor. The therapeutic effect of the arginase 1 inhibitor on tumor growth was also observed in a pre-clinical mouse model of lung cancer (99, 177). However, the tumor-promoting role of arginase 1 remains controversial as L-arginine also favors tumor cell proliferation and survival. In vitro, recombinant human arginase 1 induces cell cycle arrest and apoptosis of human tumor cell lines (178-182). Bioengineered PEGylated arginase 1 for which the half-life was extended through PEGylation, was shown to exert anti-tumor effects in xenograft mouse models $(179,181,183,184)$. Recent evidence suggests that the bioengineered human PEGylated arginase 1 (AEB1102) exerts additive anti-tumor effects when combined to anti-PD-1 or anti-PD-L1 in melanoma, small cell lung cancer (SCLC), and sarcoma patient-derived xenografts $(183,184)$. Collectively these results demonstrate that disrupting the physiological balance of L-arginine may either inhibit or promote tumor progression depending on T-cell and tumor cell susceptibility to arginine starvation. The synergistic therapeutic efficacy of either recombinant arginase 1 or arginase 1 inhibitor in combination with various chemotherapies or Pembrolizumab (anti-PD-1) is currently being tested in phase $1 / 2$ clinical trials (NCT03371979; NCT02903914; NCT03361228; NCT03314935).

\section{Tyrosine Kinase Inhibitors}

In mice, splenic HSPCs were shown to contribute to the Tcell suppressive function of TANs (131) in a murine model of HCC. Low-dose of sorafenib, a c-Kit inhibitor, was associated with increased apoptosis of splenic HSPCs and reduced immunosuppressive function of TANs. Sorafenib synergizes with PD-L1 blockade. The authors showed that the therapeutic effect of sorafenib could be largely attributed to splenic HSPCs depletion as the adoptive transfer of splenic HSPCs following sorafenib treatment abrogated its effects. In contrast, sorafenib promoted expansion of tumor-promoting TANs in the HCC mouse model and therefore limit sorafenib therapeutic efficacy (185). This finding was translatable in HCC patients, since TAN infiltration was higher in patients previously treated with sorafenib prior to liver resection, compared to untreated patients.

Another tyrosine kinase inhibitor, called sunitinib, has also shown promising results in depleting pro-tumor neutrophils. In renal cell carcinoma (RCC) patients, the elevated percentage of the T-cell suppressive CD15 ${ }^{+} \mathrm{CD} 14^{-}$LDNs among PBMCs declined in response to sunitinib treatment. In vitro, sunitinib induced the death of CD15 ${ }^{+} \mathrm{CD} 14^{-} \mathrm{LDNs}$ in a dose-dependent manner (186). Studies in mice showed that sunitinib depleted T-cell suppressive splenic neutrophils, whereas it failed to deplete T-cell suppressive TANs $(187,188)$. Intra-tumor GMCSF promotes STAT5 signaling pathway activation, which largely explains the resistance of TANs to sunitinib-induced cell death. In contrast, another group showed that sunitinib depletes tumor-associated $\mathrm{Gr}^{+}$MDSC and synergizes with a cancer vaccine to enhance antigen-specific immune responses and tumor eradication (189). However, these authors did not specify which MDSC subset (granulocytic or monocytic myeloid cells) was targeted by sunitinib.

\section{C5aR Blockade}

The C5a receptor (C5aR, CD88) becomes fairly well known for its role in immunosuppressive activity of myeloid cells. Lung cancer cells were found to produce $\mathrm{C} 5 \mathrm{a}$ which could bind to $\mathrm{C} 5 \mathrm{aR}$ expressed by myeloid cells to increase their immunosuppressive functions (190). Concentration of C5a in peripheral blood of lung cancer patients was significantly higher as compared to healthy donors. A recent pre-clinical study showed additional therapeutic effects of C5a pharmacologic inhibition in combination with PD-1 blockade unleashing anti-tumor CD8 T-cell response in a model of lung cancer (191). In this latter study, the C5a inhibitor named NOX-D21 is an 1-aptamer that tightly binds to C5a and inhibits the interaction with its receptors. Another group recently reported in a pre-clinical model of squamous cell carcinoma, that the targeting of $\mathrm{C} 5 \mathrm{aR} 1$ essentially in macrophages with a peptide antagonist (PMX-53) improved efficacy of paclitaxel chemotherapy and was associated with CD8 T cell response (192). A blocking antibody against C5aR (IPH5401) was recently developed and entered phase 1 clinical trial in combination with PD-L1 blockade for lung cancer patients (NSCLC) and head and neck patients (HCC) (NCT03665129). Recent evidence suggests that not only macrophages but also neutrophils express high level of C5aR (193). Moreover, the authors showed that IPH5401 selectively inhibited C5a-induced activation and migration of human blood neutrophils, suggesting that neutrophils may account as therapeutic target of C5aR blocking antibody.

\section{STAT3 Inhibition}

STAT3 transcription factor is well known to be important for the tumor-promoting activities of myeloid cells such as immunosuppression (194-197) or tumor angiogenesis (198). Clinical trials using small molecule inhibitors targeting STAT3 showed limited therapeutic effects and broad side effects (199). Other approach attempting to inhibit STAT3 signaling 
pathway by using STAT3 siRNA are currently evaluated in clinical trials (199). The mechanisms by which STAT3 inhibition dampens the immunosuppressive function of neutrophils are not clear. Recent evidences suggest that STAT3 activation leads to the expression of the fatty acid translocase CD36 that in turn increases the uptake of lipids and the oxidative metabolism, and subsequently the immunosuppressive function of myeloid cells $(200,201)$. Further studies will be needed to evaluate the impact of targeting STAT3 in tumor-promoting neutrophils.

\section{FATP2 Inhibition}

Recent evidences suggest that lipid metabolism could contribute to the pathological activation of G-MDSC $(201,202)$. Human TANs and peripheral blood G-MDSC also upregulate the expression of several lipid transporters such as CD36, Msr1, Ldlr, or Lox1, as compared to neutrophils from healthy donors. Addition of very low-density lipoproteins increased the Tcell suppressive function of MDSC in vitro (201). Genetic depletion of the fatty acid translocase CD36 in tumor-bearing mice delayed tumor growth in vivo (201). More recent in vivo evidence showed that genetic deletion of the SLC27A2 gene (also known as FATP2) encoding the very long-chain acylCoA synthetase, specifically in neutrophils using the S100a8cre mice, abrogated tumor growth in different tumor models (202). FATP2 ${ }^{-/}-$TANs had decreased T-cell suppressive activity as compared to WT TANs (202). The authors further showed that the selective FATP2 inhibitor lipofermata delayed tumor growth in different preclinical mouse models and synergized with either anti-CTLA4 or anti-CSF1R antibody. Human TANs were found to have a higher intracellular lipid content as compared to blood neutrophils from matched cancer patients (202). Future investigations on human samples will be needed to evaluate the clinical relevance of targeting FATP2 in cancer patients.

\section{Soluble Fas-Fc}

A pre-clinical mouse study recently reported that neutrophils upregulate Fas-L which in turn triggers apoptosis of tumorinfiltrating lymphocytes, thereby causing resistance to immunotherapies based on checkpoint blockade, cancer vaccines or adoptive T-cell therapy (104). In this study, soluble Fas-Fc neutralized Fas-L in vivo, rendering tumors sensitive to T-cell-based immunotherapies. Future studies are required to determine whether high infiltration of Fas- $\mathrm{L}$ positive TANs at baseline is associated with unresponsiveness to immunotherapies.

\section{Prevention of Neutrophil Capacity to Foster Tumor Cell Proliferation and Migration \\ Inhibition of Netosis}

A preclinical study showed that NETs promote the development and progression of liver metastases after surgical stress. Patients undergoing curative liver resection for metastatic colorectal cancer, that were characterized by an increased postoperative NET formation, had a $>4$-fold reduction in disease-free survival (59). Accelerated development and progression of metastatic disease was demonstrated in a murine model that recapitulated NET formation after surgical stress. Local treatment with DNAse 1 or inhibition of the enzyme peptidylarginine deaminase (PAD4), which is essential for NET formation, abolished tumor progression after surgery (59). There are current limitations for the use of the PAD4 inhibitor to prevent NET in vivo due to its short-half-life (86). Similar to the PAD4 inhibitor, the short half-life of NE and cathepsin $G$ inhibitors prevents their use in vivo for cancer treatment (86). Recently, NET-associated proteases, NE and matrix metalloproteinase 9, were shown to sequentially cleave laminin (85). This proteolytically remodeled laminin induced proliferation of dormant cancer cells by activating integrin $\alpha 3 \beta 1$ signaling, and antibodies against NET-remodeled laminin 111 prevented the awakening of dormant cancer cells (85). Engineering of monoclonal antibodies against human NET-remodeled laminin would help determine if such mechanisms occur in humans and whether they are correlated with patient prognosis.

\section{Arachidonate 5-Lipoxygenase (Alox5) Inhibition}

Evidences showed that neutrophil-derived leukotriene support breast cancer metastasis by selectively expanding cancer cells that retain high metastatic potential (84). Pharmacologic inhibition of arachidonate 5-lipoxyenase (Alox5) by zileuton (203) could inhibit the pro-metastatic activity of neutrophils. The authors showed that both leukotriene receptor Leukotriene B4 receptor 2 (BLT2) and Cysteinyl leukotriene receptor 2 (CysLT2) were expressed in human breast tumor and matched lymph node metastases. Future investigation will be needed to determine the therapeutic potential of such targets.

\section{Blockade of Neutrophil-Circulating Tumor Cell Interaction}

Accumulating evidence indicates that neutrophils interact with circulating tumor cells to promote their proliferation and favor their extravasation to metastatic sites $(58,61,204)$. Either NETs or VCAM1 adhesion molecules seem to be important in the interaction between neutrophils and circulating tumor cells. DNAse 1 treatment or VCAM1deficient tumor cells prevented such interaction and impaired metastasis.

\section{Promotion of the Anti-tumor Functions of Neutrophils}

\section{Antigen-Dependent Cellular Cytotoxicity (ADCC)}

Mounting evidence strongly supports the concept of targeting Fc-Receptors on neutrophils in anti-tumor immunotherapy. Although they express IgA-Fc-Receptor (CD89) and IgGFc-Receptors (CD16; CD32; CD64), evidence showed that neutrophils are more effective at mediating ADCC through IgA antibodies than IgG antibodies in vitro $(107,108,110)$. Numerous pre-clinical studies conducted in CD89 transgenic mice confirmed its superior ability to induce neutrophildependent tumor cell killing for different tumor-associated antigens, such as HER2/neu (on breast carcinoma), EpCAM 
(colon carcinoma), EGFR (epithelial carcinoma and renal cell carcinoma), HLA class II (B-cell lymphoma), CD30 (T- and Bcell lymphoma), and CD20 (B-cell lymphoma) (205). Due to its shorter half-life as compared to other serum isotypes, the engineering of IgA antibodies could be a promising therapeutic option to increase effectiveness of currently given monoclonal antibody-based immunotherapies.

\section{CONCLUSION AND PERSPECTIVES}

Although immunotherapies held great promise for oncology, only a small percentage of cancer patients showed benefits from these treatments. The search for new therapeutic targets is thus critically needed. Current immunotherapies mostly rely on the adaptive immune system, involving adaptive immune checkpoints such as CTLA-4, PD-1, and PD-L1. Recent preclinical studies suggest that innate immunity could offer new therapeutic opportunities. Inhibition of the innate immune checkpoints Tyro3, Axl, and Mertk tyrosine kinase receptors, mostly expressed by TAMs, displayed additional therapeutic effects when combined to the anti-PD-1 monoclonal antibody in a murine model of triple-negative breast cancer (206). Accumulating evidence suggests that neutrophils may be ideal targets for future therapeutic strategies. Several groups reported that the selective depletion of neutrophils could delay tumor growth. Ongoing pre-clinical investigations aim at evaluating the potential synergistic effect of neutrophil depletion with currently approved immunotherapies. In cancer patients, accumulating evidence from retrospective studies supports a rationale for eliminating neutrophils. Indeed, several approved cancer drugs were shown to deplete neutrophils and were associated with a better survival. Nonetheless, we cannot rule-out off-target therapeutic effects of these drugs. Moreover, blood neutrophil count is routinely used as a read-out of cancer treatmentrelated toxicities, since neutrophils are important in the immune response upon bacterial infection. Further studies are therefore needed to identify pro-tumor neutrophil-associated targets non-overlapping with antibacterial neutrophils, to enhance therapeutic efficacy of immunotherapies while minimizing side effects.

While the elimination of neutrophils seems to provide therapeutic effects in established tumor models, emerging evidence favors an anti-tumor role for neutrophils in earlystage tumors in mice $(78,114,115)$. Evidence from retrospective studies and ex vivo functional analyses also support the concept of an anti-tumor role for neutrophils in early-stage human tumors. Although challenging, access to early-stage tumors will be original and fundamental to gain new insights into potentially novel yet undiscovered phenotypes and functions of TANs. With such diverse roles, the ideal targeting of neutrophils in oncology would be to promote the enrichment of anti-tumor neutrophils while depleting pro-tumor ones without altering antibacterial neutrophils.

The current dogma in cancer immunotherapy mainly relies on restoring anti-tumor T-cell response. However, a high tumor infiltration by anti-tumor lymphocytes is not sufficient to eradicate all tumor clones during the course of metastasis as for example in colorectal cancer patients, shedding light on tumorintrinsic and tumor-extrinsic mechanisms of escape that remain to be discovered (207). Resistance to CD8 T cell-induced tumor cell death by ferroptosis can be one possible tumor cell-intrinsic mechanism of escape (194). Neutrophils can kill tumor cells in a non-apoptotic mechanism by a process called trogoptosis, distinct from ferroptosis by its lytic/necrotic form (208) of cell death that may release DAMP and tumor (neo) antigens from the killed cancer cells (111). Neutrophils could therefore improve cytotoxic T cell response to eliminate resistant tumor clones.

Beyond their role at tumor site, neutrophils seem to promote tumor progression by acting systemically as exemplified by the ability of blood neutrophils to escort circulating tumor cells within the bloodstream and facilitate their extravasation to metastatic site (56-61). Moreover, the T-cell suppressive activity of circulating neutrophils is restricted to in vitro studies. It remains to be known if such neutrophil-mediated T-cell suppression occurs in blood in vivo. Growing evidences also highlight the importance of distant microenvironment away from tumor bed such as the bone marrow and the spleen to educate pro-tumor TANs $(130,131)$. Future studies should therefore consider the importance of the different microenvironments outside of the tumor bed, regarding the origin and function of neutrophils in cancer, for the benefits of patients.

\section{AUTHOR CONTRIBUTIONS}

PL, MS, MP, and JM wrote the original draft of manuscript. $\mathrm{PL}$ performed original figures and overall the supervision of writing. LK, CC, NB-V, and M-CM revised and edited the manuscript.

\section{FUNDING}

Our work was supported by grant from INCa-Fondation ARCLigue contre le cancer PAIR SEIN n ${ }^{\circ}$ 2014-093, by grants INCa PLBio $n^{\circ}$ 2017-158, by grants Ligue contre le cancer CCAURA by grant FRM n ${ }^{\circ}$ SPF20160936218, French Government PhD Fellowship (2016-2019), and 1-year extension Ph.D. Fellowship from Ligue Nationale contre le cancer (2019/2020). We also want to thank the Plan Cancer (INCa-ITMO Cancer), the LABEX DEVweCAN (ANR-10-LABX-0061) of the University of Lyon and the RHU MyPROBE (ANR-17-RHUS-0008), both within the program Investissements d'Avenir organized by the French National Research Agency (ANR), and the LYRICAN (grant INCa-DGOS-Inserm_12563).

\section{ACKNOWLEDGMENTS}

We thank Brigitte Manship, our scientific writer for final proofreading and Vincent Alcazer for careful reading of the manuscript and helpful comments and suggestions. 


\section{REFERENCES}

1. Hanahan D, Weinberg RA. Hallmarks of cancer: the next generation. Cell. (2011) 144:646-74. doi: 10.1016/j.cell.2011.02.013

2. Balkwill F, Mantovani A. Cancer and inflammation: implications for pharmacology and therapeutics. Clin Pharmacol Ther. (2010) 87:4016. doi: 10.1038/clpt.2009.312

3. Diakos CI, Charles KA, McMillan DC, Clarke SJ. Cancer-related inflammation and treatment effectiveness. Lancet Oncol. (2014) 15:e493-503. doi: 10.1016/S1470-2045(14)70263-3

4. Gabrilovich DI, Ostrand-Rosenberg S, Bronte V. Coordinated regulation of myeloid cells by tumours. Nat Rev Immunol. (2012) 12:253-68. doi: $10.1038 / \mathrm{nri3} 175$

5. Borregaard N. Neutrophils, from marrow to microbes. Immunity. (2010) 33:657-70. doi: 10.1016/j.immuni.2010.11.011

6. Mestas J, Hughes CCW. Of Mice and not men: differences between mouse and human immunology. J Immunol. (2004) 172:2731-8. doi: 10.4049/jimmunol.172.5.2731

7. Li Y, Klippel Z, Shih X, Wang H, Reiner M, Page JH. Trajectory of absolute neutrophil counts in patients treated with pegfilgrastim on the day of chemotherapy versus the day after chemotherapy. Cancer Chemother Pharmacol. (2016) 77:703-12. doi: 10.1007/s00280-016-2970-5

8. Klastersky J, de Naurois J, Rolston K, Rapoport B, Maschmeyer G, Aapro M, et al. Management of febrile neutropaenia: ESMO clinical practice guidelines. Ann Oncol. (2016) 27:v111-8. doi: 10.1093/annonc/mdw325

9. Templeton AJ, McNamara MG, Šeruga B, Vera-Badillo FE, Aneja P, Ocaña A, et al. Prognostic role of neutrophil-to-lymphocyte ratio in solid tumors: a systematic review and meta-analysis. J Natl Cancer Inst. (2014) 106:dju124. doi: 10.1093/jnci/dju124

10. Paramanathan A, Saxena A, Morris DL. A systematic review and metaanalysis on the impact of pre-operative neutrophil lymphocyte ratio on long term outcomes after curative intent resection of solid tumours. Surg Oncol. (2014) 23:31-9. doi: 10.1016/j.suronc.2013.12.001

11. Vano Y-A, Oudard S, By M-A, Têtu P, Thibault C, Aboudagga H, et al. Optimal cut-off for neutrophil-to-lymphocyte ratio: Fact or Fantasy? A prospective cohort study in metastatic cancer patients. PLoS ONE. (2018) 13:e0195042. doi: 10.1371/journal.pone.0195042

12. Nakamura Y, Watanabe R, Katagiri M, Saida Y, Katada N, Watanabe $\mathrm{M}$, et al. Neutrophil/lymphocyte ratio has a prognostic value for patients with terminal cancer. World J Surg Oncol. (2016) 14:148. doi: 10.1186/s12957-016-0904-7

13. Chua W, Charles KA, Baracos VE, Clarke SJ. Neutrophil/lymphocyte ratio predicts chemotherapy outcomes in patients with advanced colorectal cancer. Br J Cancer. (2011) 104:1288-95. doi: 10.1038/bjc.2011.100

14. Michael M, Goldstein D, Clarke SJ, Milner AD, Beale P, Friedlander M, et al. Prognostic factors predictive of response and survival to a modified FOLFOX regimen: importance of an increased neutrophil count. Clin Colorectal Cancer. (2006) 6:297-304. doi: 10.3816/CCC.2006.n.048

15. Chae S, Kang KM, Kim HJ, Kang E, Park SY, Kim JH, et al. Neutrophillymphocyte ratio predicts response to chemotherapy in triple-negative breast cancer. Curr Oncol Tor Ont. (2018) 25:e113-9. doi: 10.3747/co.25.3888

16. Chua W, Clarke SJ, Charles KA. Systemic inflammation and prediction of chemotherapy outcomes in patients receiving docetaxel for advanced cancer. Support Care Cancer. (2012) 20:1869-74. doi: 10.1007/s00520-011-1289-3

17. Kaito S, Kanemasa Y, Sasaki Y, Okuya T, Yamaguchi T, Funasaka C, et al. A new prognostic score comprising lactate dehydrogenase, albumin and neutrophil to lymphocyte ratio to predict sensitivity to first-line chemotherapy in patients with peripheral T-cell lymphomas. Int J Hematol. (2018) 107:451-9. doi: 10.1007/s12185-017-2362-6

18. Dell'Aquila E, Cremolini C, Zeppola T, Lonardi S, Bergamo F, Masi G, et al. Prognostic and predictive role of neutrophil/lymphocytes ratio in metastatic colorectal cancer: a retrospective analysis of the TRIBE study by GONO. Ann Oncol. (2018) 29:924-30. doi: 10.1093/annonc/mdy004

19. Cho K-M, Park H, Oh D-Y, Kim T-Y, Lee K-H, Han S-W, et al. Neutrophil-to-lymphocyte ratio, platelet-to-lymphocyte ratio, and their dynamic changes during chemotherapy is useful to predict a more accurate prognosis of advanced biliary tract cancer. Oncotarget. (2017) 8:232941. doi: 10.18632/oncotarget.13731
20. Sümbül AT, Sezer A, Abali H, Köse F, Gültepe I, Mertsoylu H, et al. Neutrophil-to-lymphocyte ratio predicts PSA response, but not outcomes in patients with castration-resistant prostate cancer treated with docetaxel. Int Urol Nephrol. (2014) 46:1531-5. doi: 10.1007/s11255-014-0664-7

21. Templeton AJ, Knox JJ, Lin X, Simantov R, Xie W, Lawrence N, et al. Change in neutrophil-to-lymphocyte ratio in response to targeted therapy for metastatic renal cell carcinoma as a prognosticator and biomarker of efficacy. Eur Urol. (2016) 70:358-64. doi: 10.1016/j.eururo.2016.02.033

22. Lin G-N, Peng J-W, Liu P-P, Liu D-Y, Xiao J-J, Chen X-Q. Elevated neutrophil-to-lymphocyte ratio predicts poor outcome in patients with advanced non-small-cell lung cancer receiving first-line gefitinib or erlotinib treatment. Asia Pac J Clin Oncol. (2017) 13:e189-94. doi: 10.1111/ajco.12273

23. Meriggi F, Codignola C, Beretta GD, Ceresoli GL, Caprioli A, Scartozzi M, et al. Significance of neutrophil-to-lymphocyte ratio in Western advanced EGFR-mutated non-small cell lung cancer receiving a targeted therapy. Tumori. (2017) 103:443-8. doi: 10.5301/tj.5000632

24. Zhang Y, Feng Y-C, Zhu H-G, Xiong T-C, Hou Y-S, Song J, et al. The peripheral blood neutrophil-to-lymphocyte ratio is a prognostic predictor for survival of EGFR-mutant nonsmall cell lung cancer patients treated with EGFR-TKIs. Medicine. (2018) 97:e11648. doi: 10.1097/MD.0000000000011648

25. Rutkowski P, Teterycz P, Klimczak A, Bylina E, Szamotulska K, Lugowska I. Blood neutrophil-to-lymphocyte ratio is associated with prognosis in advanced gastrointestinal stromal tumors treated with imatinib. Tumori. (2018) 104:415-22. doi: 10.1177/0300891618765543

26. Kobayashi H, Okuma T, Oka H, Hirai T, Ohki T, Ikegami M, et al. Neutrophil-to-lymphocyte ratio after pazopanib treatment predicts response in patients with advanced soft-tissue sarcoma. Int J Clin Oncol. (2018) 23:368-74. doi: 10.1007/s10147-017-1199-6

27. Wei K, Wang M, Zhang W, Mu H, Song TQ. Neutrophil-lymphocyte ratio as a predictor of outcomes for patients with hepatocellular carcinoma undergoing TAE combined with Sorafenib. Med Oncol Northwood Lond Engl. (2014) 31:969. doi: 10.1007/s12032-014-0969-5

28. da Fonseca LG, Barroso-Sousa R, Bento A da SA, Blanco BP, Valente GL, Pfiffer TEF, et al. Pre-treatment neutrophil-to-lymphocyte ratio affects survival in patients with advanced hepatocellular carcinoma treated with sorafenib. Med Oncol Northwood Lond Engl. (2014) 31:264. doi: 10.1007/s12032-014-0264-5

29. Robert C, Long GV, Brady B, Dutriaux C, Maio M, Mortier L, et al. Nivolumab in previously untreated melanoma without BRAF mutation. $N$ Engl J Med. (2015) 372:320-30. doi: 10.1056/NEJMoa1412082

30. Borghaei H, Paz-Ares L, Horn L, Spigel DR, Steins M, Ready NE, et al. Nivolumab versus docetaxel in advanced nonsquamous non-small-cell lung cancer. N Engl J Med. (2015) 373:1627-39. doi: 10.1056/NEJMoa1507643

31. Ferrucci PF, Gandini S, Battaglia A, Alfieri S, Di Giacomo AM, Giannarelli $\mathrm{D}$, et al. Baseline neutrophil-to-lymphocyte ratio is associated with outcome of ipilimumab-treated metastatic melanoma patients. Br J Cancer. (2015) 112:1904-10. doi: 10.1038/bjc.2015.180

32. Capone M, Giannarelli D, Mallardo D, Madonna G, Festino L, Grimaldi AM, et al. Baseline neutrophil-to-lymphocyte ratio (NLR) and derived NLR could predict overall survival in patients with advanced melanoma treated with nivolumab. J Immunother Cancer. (2018) 6:74. doi: 10.1186/s40425-018-0383-1

33. Buder-Bakhaya K, Hassel JC. Biomarkers for clinical benefit of immune checkpoint inhibitor treatment-A review from the melanoma perspective and beyond. Front Immunol. (2018) 9:1474. doi: 10.3389/fimmu.2018.01474

34. Cassidy MR, Wolchok RE, Zheng J, Panageas KS, Wolchok JD, Coit D, et al. Neutrophil to lymphocyte ratio is associated with outcome during ipilimumab treatment. EBioMedicine. (2017) 18:56-61. doi: 10.1016/j.ebiom.2017.03.029

35. Brahmer J, Reckamp KL, Baas P, Crinò L, Eberhardt WEE, Poddubskaya E, et al. Nivolumab versus docetaxel in advanced squamous-cell non-small-cell lung cancer. N Engl J Med. (2015) 373:123-35. doi: 10.1056/NEJMoa1504627

36. Diem S, Schmid S, Krapf M, Flatz L, Born D, Jochum W, et al. Neutrophil-to-Lymphocyte ratio (NLR) and Platelet-to-Lymphocyte ratio (PLR) as prognostic markers in patients with non-small cell lung cancer (NSCLC) treated with nivolumab. Lung Cancer Amst Neth. (2017) 111:17681. doi: 10.1016/j.lungcan.2017.07.024 
37. Ameratunga M, Chénard-Poirier M, Moreno Candilejo I, Pedregal M, Lui A, Dolling D, et al. Neutrophil-lymphocyte ratio kinetics in patients with advanced solid tumours on phase I trials of PD-1/PD-L1 inhibitors. Eur J Cancer. (2018) 89:56-63. doi: 10.1016/j.ejca.2017.11.012

38. Schernberg A, Mezquita L, Boros A, Botticella A, Caramella C, Besse B, et al. Neutrophilia as prognostic biomarker in locally advanced stage III lung cancer. PLoS ONE. (2018) 13:e0204490. doi: 10.1371/journal.pone.0204490

39. Ma J, Kuzman J, Ray A, Lawson BO, Khong B, Xuan S, et al. Neutrophil-tolymphocyte Ratio (NLR) as a predictor for recurrence in patients with stage III melanoma. Sci Rep. (2018) 8:4044. doi: 10.1038/s41598-018-22425-3

40. Li Z, Zhao R, Cui Y, Zhou Y, Wu X. The dynamic change of neutrophil to lymphocyte ratio can predict clinical outcome in stage I-III colon cancer. Sci Rep. (2018) 8:9453. doi: 10.1038/s41598-018-27896-y

41. Wu C-N, Chuang H-C, Lin Y-T, Fang F-M, Li S-H, Chien C-Y. Prognosis of neutrophil-to-lymphocyte ratio in clinical early-stage tongue (cT1/T2N0) cancer. Onco Targets Ther. (2017) 10:3917-24. doi: 10.2147/OTT.S140800

42. Orditura M, Galizia G, Diana A, Saccone C, Cobellis L, Ventriglia J, et al. Neutrophil to lymphocyte ratio (NLR) for prediction of distant metastasis-free survival (DMFS) in early breast cancer: a propensity score-matched analysis. ESMO Open. (2016) 1:e000038. doi: 10.1136/esmoopen-2016-000038

43. Chu MO, Shen C-H, Chang T-S, Xu H-W, Yen C-W, Lu S-N, et al. Pretreatment inflammation-based markers predict survival outcomes in patients with early stage hepatocellular carcinoma after radiofrequency ablation. Sci Rep. (2018) 8:16611. doi: 10.1038/s41598-018-34543-Z

44. Sagiv JY, Michaeli J, Assi S, Mishalian I, Kisos H, Levy L, et al. Phenotypic diversity and plasticity in circulating neutrophil subpopulations in cancer. Cell Rep. (2015) 10:562-73. doi: 10.1016/j.celrep.2014.12.039

45. Bronte V, Brandau S, Chen S-H, Colombo MP, Frey AB, Greten $\mathrm{TF}$, et al. Recommendations for myeloid-derived suppressor cell nomenclature and characterization standards. Nat Commun. (2016) 7:12150. doi: 10.1038/ncomms12150

46. Rodriguez PC, Ernstoff MS, Hernandez C, Atkins M, Zabaleta J, Sierra R, et al. Arginase I-producing myeloid-derived suppressor cells in renal cell carcinoma are a subpopulation of activated granulocytes. Cancer Res. (2009) 69:1553-60. doi: 10.1158/0008-5472.CAN-08-1921

47. Brandau S, Trellakis S, Bruderek K, Schmaltz D, Steller G, Elian M, et al. Myeloid-derived suppressor cells in the peripheral blood of cancer patients contain a subset of immature neutrophils with impaired migratory properties. J Leukoc Biol. (2011) 89:311-7. doi: 10.1189/jlb.0310162

48. Condamine T, Dominguez GA, Youn J-I, Kossenkov AV, Mony S, AliceaTorres K, et al. Lectin-type oxidized LDL receptor-1 distinguishes population of human polymorphonuclear myeloid-derived suppressor cells in cancer patients. Sci Immunol. (2016) 1:aaf8943. doi: 10.1126/sciimmunol.aaf8943

49. Lang S, Bruderek K, Kaspar C, Höing B, Kanaan O, Dominas N, et al. Clinical relevance and suppressive capacity of human myeloidderived suppressor cell subsets. Clin Cancer Res. (2018) 24:483444. doi: 10.1158/1078-0432.CCR-17-3726

50. Gabrilovich DI. Myeloid-derived suppressor cells. Cancer Immunol Res. (2017) 5:3-8. doi: 10.1158/2326-6066.CIR-16-0297

51. Ouzounova M, Lee E, Piranlioglu R, El Andaloussi A, Kolhe R, Demirci $\mathrm{MF}$, et al. Monocytic and granulocytic myeloid derived suppressor cells differentially regulate spatiotemporal tumour plasticity during metastatic cascade. Nat Commun. (2017) 8:14979. doi: 10.1038/ncomms14979

52. Pillay J, Kamp VM, Hoffen E van, Visser T, Tak T, Lammers J$\mathrm{W}$, et al. A subset of neutrophils in human systemic inflammation inhibits T cell responses through Mac-1. J Clin Invest. (2012) 122:32736. doi: 10.1172/JCI57990

53. Evrard M, Kwok IWH, Chong SZ, Teng KWW, Becht E, Chen J, et al. Developmental analysis of bone marrow neutrophils reveals populations specialized in expansion, trafficking, and effector functions. Immunity. (2018) 48:364-79.e8. doi: 10.1016/j.immuni.2018. 02.002

54. Zhu YP, Padgett L, Dinh HQ, Marcovecchio P, Blatchley A, $\mathrm{Wu} \mathrm{R}$, et al. Identification of an early unipotent neutrophil progenitor with pro-tumoral activity in mouse and human bone marrow. Cell Rep. (2018) 24:2329-41.e8. doi: 10.1016/j.celrep.2018. 07.097
55. Marini O, Costa S, Bevilacqua D, Calzetti F, Tamassia N, Spina C, et al. Mature $\mathrm{CD}_{10}{ }^{+}$and immature $\mathrm{CD}^{-}$neutrophils present in G-CSFtreated donors display opposite effects on T cells. Blood. (2017) 129:134356. doi: 10.1182/blood-2016-04-713206

56. Huh SJ, Liang S, Sharma A, Dong C, Robertson GP. Transiently entrapped circulating tumor cells interact with neutrophils to facilitate lung metastasis development. Cancer Res. (2010) 70:6071-82. doi: 10.1158/0008-5472.CAN-09-4442

57. Spicer JD, McDonald B, Cools-Lartigue JJ, Chow SC, Giannias B, Kubes $\mathrm{P}$, et al. Neutrophils promote liver metastasis via Mac-1-mediated interactions with circulating tumor cells. Cancer Res. (2012) 72:391927. doi: 10.1158/0008-5472.CAN-11-2393

58. Cools-Lartigue J, Spicer J, McDonald B, Gowing S, Chow S, Giannias B, et al. Neutrophil extracellular traps sequester circulating tumor cells and promote metastasis. J Clin Invest. (2013) 123:67484. doi: 10.1172/JCI67484

59. Tohme S, Yazdani HO, Al-Khafaji AB, Chidi AP, Loughran P, Mowen $\mathrm{K}$, et al. Neutrophil extracellular traps promote the development and progression of liver metastases after surgical stress. Cancer Res. (2016) 76:1367-80. doi: 10.1158/0008-5472.CAN-15-1591

60. Chen MB, Hajal C, Benjamin DC, Yu C, Azizgolshani H, Hynes RO, et al. Inflamed neutrophils sequestered at entrapped tumor cells via chemotactic confinement promote tumor cell extravasation. Proc Natl Acad Sci USA. (2018) 115:7022-7. doi: 10.1073/pnas.1715932115

61. Szczerba BM, Castro-Giner F, Vetter M, Krol I, Gkountela S, Landin J, et al Neutrophils escort circulating tumour cells to enable cell cycle progression. Nature. (2019) 566:553-7. doi: 10.1038/s41586-019-0915-y

62. Jensen HK, Donskov F, Marcussen N, Nordsmark M, Lundbeck F, von der Maase H. Presence of intratumoral neutrophils is an independent prognostic factor in localized renal cell carcinoma. J Clin Oncol. (2009) 27:4709-17. doi: 10.1200/JCO.2008.18.9498

63. Rao H-L, Chen J-W, Li M, Xiao Y-B, Fu J, Zeng Y-X, et al. Increased intratumoral neutrophil in colorectal carcinomas correlates closely with malignant phenotype and predicts patients' adverse prognosis. PLoS ONE. (2012) 7:e30806. doi: 10.1371/journal.pone.0030806

64. Trellakis S, Bruderek K, Dumitru CA, Gholaman H, Gu X, Bankfalvi A, et al. Polymorphonuclear granulocytes in human head and neck cancer: enhanced inflammatory activity, modulation by cancer cells and expansion in advanced disease. Int J Cancer. (2011) 129:2183-93. doi: 10.1002/ijc.25892

65. Matsumoto Y, Mabuchi S, Kozasa K, Kuroda H, Sasano T, Yokoi E, et al. The significance of tumor-associated neutrophil density in uterine cervical cancer treated with definitive radiotherapy. Gynecol Oncol. (2017) 145:46975. doi: 10.1016/j.ygyno.2017.02.009

66. Galdiero MR, Varricchi G, Loffredo S, Bellevicine C, Lansione T, Ferrara AL, et al. Potential involvement of neutrophils in human thyroid cancer. PLoS ONE. (2018) 13:e0199740. doi: 10.1371/journal.pone.0199740

67. Caruso RA, Bellocco R, Pagano M, Bertoli G, Rigoli L, Inferrera C. Prognostic value of intratumoral neutrophils in advanced gastric carcinoma in a high-risk area in northern Italy. Mod Pathol. (2002) 15:8317. doi: 10.1097/01.MP.0000020391.98998.6B

68. Galdiero MR, Bianchi P, Grizzi F, Di Caro G, Basso G, Ponzetta A, et al. Occurrence and significance of tumor-associated neutrophils in patients with colorectal cancer. Int J Cancer. (2016) 139:446-56. doi: 10.1002/ijc.30076

69. Droeser RA, Hirt C, Eppenberger-Castori S, Zlobec I, Viehl CT, Frey $\mathrm{DM}$, et al. High myeloperoxidase positive cell infiltration in colorectal cancer is an independent favorable prognostic factor. PLoS ONE. (2013) 8:e64814. doi: 10.1371/journal.pone.0064814

70. Li B, Severson E, Pignon J-C, Zhao H, Li T, Novak J, et al. Comprehensive analyses of tumor immunity: implications for cancer immunotherapy. Genome Biol. (2016) 17:174. doi: 10.1186/s13059-016-1028-7

71. Torsteinsdóttir I, Arvidson NG, Hällgren R, Håkansson L. Enhanced expression of integrins and CD66b on peripheral blood neutrophils and eosinophils in patients with rheumatoid arthritis, and the effect of glucocorticoids. Scand J Immunol. (1999) 50:433-9. doi: 10.1046/j.1365-3083.1999.00602.x

72. Bochner BS, Sterbinsky SA, Bickel CA, Werfel S, Wein M, Newman W. Differences between human eosinophils and neutrophils in the function and expression of sialic acid-containing counterligands for E-selectin. J Immunol. (1994) 152:774-82 
73. Dollery CM, Owen CA, Sukhova GK, Krettek A, Shapiro SD, Libby P. Neutrophil elastase in human atherosclerotic plaques: production by macrophages. Circulation. (2003) 107:282936. doi: 10.1161/01.CIR.0000072792.65250.4A

74. Shepherd J, Hilderbrand SA, Waterman P, Heinecke JW, Weissleder R, Libby P. A fluorescent probe for the detection of myeloperoxidase activity in atherosclerosis-associated macrophages. Chem Biol. (2007) 14:122131. doi: 10.1016/j.chembiol.2007.10.005

75. Li L, Xu L, Yan J, Zhen Z-J, Ji Y, Liu C-Q, et al. CXCR2-CXCL1 axis is correlated with neutrophil infiltration and predicts a poor prognosis in hepatocellular carcinoma. J Exp Clin Cancer Res. (2015) 34:129. doi: 10.1186/s13046-015-0247-1

76. Mantovani A, Marchesi F, Malesci A, Laghi L, Allavena P. Tumor-associated macrophages as treatment targets in oncology. Nat Rev Clin Oncol. (2017) 14:399-416. doi: 10.1038/nrclinonc.2016.217

77. Finotello F, Trajanoski Z. Quantifying tumor-infiltrating immune cells from transcriptomics data. Cancer Immunol Immunother. (2018) 67:103140. doi: 10.1007/s00262-018-2150-z

78. Blaisdell A, Crequer A, Columbus D, Daikoku T, Mittal K, Dey SK, et al. Neutrophils oppose uterine epithelial carcinogenesis via debridement of hypoxic tumor cells. Cancer Cell. (2015) 28:78599. doi: 10.1016/j.ccell.2015.11.005

79. Ponzetta A, Carriero R, Carnevale S, Barbagallo M, Molgora M, Perucchini $\mathrm{C}$, et al. Neutrophils driving unconventional $\mathrm{T}$ cells mediate resistance against murine sarcomas and selected human tumors. Cell. (2019) 178:34660. doi: 10.1016/j.cell.2019.05.047

80. Newman AM, Liu CL, Green MR, Gentles AJ, Feng W, Xu Y, et al. Robust enumeration of cell subsets from tissue expression profiles. Nat Methods. (2015) 12:453-7. doi: 10.1038/nmeth.3337

81. Gentles AJ, Newman AM, Liu CL, Bratman SV, Feng W, Kim D, et al. The prognostic landscape of genes and infiltrating immune cells across human cancers. Nat Med. (2015) 21:938-45. doi: 10.1038/nm.3909

82. Di Mitri D, Toso A, Chen JJ, Sarti M, Pinton S, Jost TR, et al. Tumour-infiltrating Gr-1+ myeloid cells antagonize senescence in cancer. Nature. (2014) 515:134-7. doi: 10.1038/nature 13638

83. Houghton AM, Rzymkiewicz DM, Ji H, Gregory AD, Egea EE, Metz HE, et al. Neutrophil elastase-mediated degradation of IRS-1 accelerates lung tumor growth. Nat Med. (2010) 16:219-23. doi: 10.1038/nm.2084

84. Wculek SK, Malanchi I. Neutrophils support lung colonization of metastasis-initiating breast cancer cells. Nature. (2015) 528:413-7. doi: 10.1038/nature 16140

85. Albrengues J, Shields MA, Ng D, Park CG, Ambrico A, Poindexter $\mathrm{ME}$, et al. Neutrophil extracellular traps produced during inflammation awaken dormant cancer cells in mice. Science. (2018) 361:eaao4227. doi: 10.1126/science.aao4227

86. Park J, Wysocki RW, Amoozgar Z, Maiorino L, Fein MR, Jorns J, et al. Cancer cells induce metastasis-supporting neutrophil extracellular DNA traps. Sci Transl Med. (2016) 8:361ra138. doi: 10.1126/scitranslmed.aag1711

87. Faget J, Groeneveld S, Boivin G, Sankar M, Zangger N, Garcia M, et al. Neutrophils and snail orchestrate the establishment of a protumor microenvironment in lung cancer. Cell Rep. (2017) 21:3190204. doi: 10.1016/j.celrep.2017.11.052

88. Wang Y, Chen J, Yang L, Li J, Wu W, Huang $\mathrm{M}$, et al. Tumor-contacted neutrophils promote metastasis by a CD90TIMP-1 juxtacrine-paracrine loop. Clin Cancer Res. (2019) 25:1957-69. doi: 10.1158/1078-0432.CCR-18-2544

89. Jablonska J, Leschner S, Westphal K, Lienenklaus S, Weiss S. Neutrophils responsive to endogenous IFN-beta regulate tumor angiogenesis and growth in a mouse tumor model. J Clin Invest. (2010) 120:115164. doi: 10.1172/JCI37223

90. Huo X, Li H, Li Z, Yan C, Agrawal I, Mathavan S, et al. Transcriptomic profiles of tumor-associated neutrophils reveal prominent roles in enhancing angiogenesis in liver tumorigenesis in zebrafish. Sci Rep. (2019) 9:1509. doi: 10.1038/s41598-018-36605-8

91. Fridlender ZG, Sun J, Kim S, Kapoor V, Cheng G, Ling L, et al. Polarization of tumor-associated neutrophil phenotype by TGF-beta: "N1" versus "N2" TAN. Cancer Cell. (2009) 16:183-94. doi: 10.1016/j.ccr.2009.06.017
92. Shaul ME, Levy L, Sun J, Mishalian I, Singhal S, Kapoor V, et al. Tumor-associated neutrophils display a distinct N1 profile following TGF $\beta$ modulation: a transcriptomics analysis of pro- vs. antitumor TANs. Oncoimmunology. (2016) 5:e1232221. doi: 10.1080/2162402X.2016.1232221

93. Schruefer R, Lutze N, Schymeinsky J, Walzog B. Human neutrophils promote angiogenesis by a paracrine feedforward mechanism involving endothelial interleukin-8. Am J Physiol Heart Circ Physiol. (2005) 288:H1186-92. doi: 10.1152/ajpheart.00237.2004

94. Aldabbous L, Abdul-Salam V, McKinnon T, Duluc L, Pepke-Zaba J, Southwood M, et al. Neutrophil extracellular traps promote angiogenesis: evidence from vascular pathology in pulmonary hypertension. Arterioscler Thromb Vasc Biol. (2016) 36:2078-87. doi: 10.1161/ATVBAHA.116.307634

95. Li T-J, Jiang Y-M, Hu Y-F, Huang L, Yu J, Zhao L-Y, et al. Interleukin-17producing neutrophils link inflammatory stimuli to disease progression by promoting angiogenesis in gastric cancer. Clin Cancer Res. (2017) 23:157585. doi: 10.1158/1078-0432.CCR-16-0617

96. Kikuchi R, Nakamura K, MacLauchlan S, Ngo DT-M, Shimizu I, Fuster $\mathrm{JJ}$, et al. An anti-angiogenic isoform of VEGF-A contributes to impaired vascularization in peripheral artery disease. Nat Med. (2014) 20:146471. doi: $10.1038 / \mathrm{nm} .3703$

97. Loffredo S, Borriello F, Iannone R, Ferrara AL, Galdiero MR, Gigantino $\mathrm{V}$, et al. Group V secreted phospholipase A2 induces the release of proangiogenic and antiangiogenic factors by human neutrophils. Front Immunol. (2017) 8:443. doi: 10.3389/fimmu.2017.00443

98. Coffelt SB, Kersten K, Doornebal CW, Weiden J, Vrijland K, Hau C-S, et al. IL-17-producing $\gamma \delta \mathrm{T}$ cells and neutrophils conspire to promote breast cancer metastasis. Nature. (2015) 522:345-8. doi: 10.1038/nature14282

99. Rodriguez PC, Quiceno DG, Zabaleta J, Ortiz B, Zea AH, Piazuelo MB, et al. Arginase I production in the tumor microenvironment by mature myeloid cells inhibits T-cell receptor expression and antigen-specific T-cell responses. Cancer Res. (2004) 64:5839-49. doi: 10.1158/0008-5472.CAN-04-0465

100. Arlauckas SP, Garren SB, Garris CS, Kohler RH, Oh J, Pittet MJ, et al. Arg1 expression defines immunosuppressive subsets of tumor-associated macrophages. Theranostics. (2018) 8:5842-54. doi: 10.7150/thno.26888

101. Zilionis R, Engblom C, Pfirschke C, Savova V, Zemmour D, Saatcioglu HD, et al. Single-cell transcriptomics of human and mouse lung cancers reveals conserved myeloid populations across individuals and species. Immunity. (2019) 50:1317-34. doi: 10.1016/j.immuni.2019.03.009

102. Raber P, Ochoa AC, Rodríguez PC. Metabolism of L-arginine by myeloid-derived suppressor cells in cancer: mechanisms of $\mathrm{T}$ cell suppression and therapeutic perspectives. Immunol Invest. (2012) 41:61434. doi: 10.3109/08820139.2012.680634

103. Michaeli J, Shaul ME, Mishalian I, Hovav A-H, Levy L, Zolotriov $\mathrm{L}$, et al. Tumor-associated neutrophils induce apoptosis of nonactivated CD8 T-cells in a TNF $\alpha$ and NO-dependent mechanism, promoting a tumor-supportive environment. Oncoimmunology. (2017) 6:e1356965. doi: 10.1080/2162402X.2017.1356965

104. Zhu J, Tenbossche CGP de, Cané S, Colau D, Baren N van, Lurquin C, et al. Resistance to cancer immunotherapy mediated by apoptosis of tumor-infiltrating lymphocytes. Nat Commun. (2017) 8:1404. doi: 10.1038/s41467-017-00784-1

105. Takeshima T, Pop LM, Laine A, Iyengar P, Vitetta ES, Hannan R. Key role for neutrophils in radiation-induced antitumor immune responses: potentiation with G-CSF. Proc Natl Acad Sci USA. (2016) 113:113005. doi: 10.1073/pnas.1613187113

106. Arelaki S, Arampatzioglou A, Kambas K, Papagoras C, Miltiades P, Angelidou I, et al. Gradient infiltration of neutrophil extracellular traps in colon cancer and evidence for their involvement in tumour growth. PLoS ONE. (2016) 11:e0154484. doi: 10.1371/journal.pone.0154484

107. Valerius T, Stockmeyer B, van Spriel AB, Graziano RF, van den Herik-Oudijk IE, Repp R, et al. FcalphaRI (CD89) as a novel trigger molecule for bispecific antibody therapy. Blood. (1997) 90:4485-92.

108. Dechant M, Vidarsson G, Stockmeyer B, Repp R, Glennie MJ, Gramatzki $M$, et al. Chimeric IgA antibodies against HLA class II effectively trigger lymphoma cell killing. Blood. (2002) 100:4574-80. doi: 10.1182/blood-2002-03-0687

109. Otten MA, Rudolph E, Dechant M, Tuk CW, Reijmers RM, Beelen RHJ, et al. Immature neutrophils mediate tumor cell 
killing via IgA but not IgG Fc receptors. J Immunol. (2005) 174:5472-80. doi: 10.4049/jimmunol.174.9.5472

110. Lohse S, Brunke C, Derer S, Peipp M, Boross P, Kellner C, et al. Characterization of a mutated IgA2 antibody of the $\mathrm{m}(1)$ allotype against the epidermal growth factor receptor for the recruitment of monocytes and macrophages. J Biol Chem. (2012) 287:25139-50. doi: 10.1074/jbc.M112.353060

111. Matlung HL, Babes L, Zhao XW, van Houdt M, Treffers LW, van Rees DJ, et al. Neutrophils kill antibody-opsonized cancer cells by trogoptosis. Cell Rep. (2018) 23:3946-59.e6. doi: 10.1016/j.celrep.2018.05.082

112. Zhang Y, Lee C, Geng S, Li L. Enhanced tumor immune surveillance through neutrophil reprogramming due to Tollip deficiency. JCI Insight. (2019) 4:122939. doi: $10.1172 /$ jci.insight.122939

113. Governa V, Trella E, Mele V, Tornillo L, Amicarella F, Cremonesi E, et al. The interplay between neutrophils and $\mathrm{CD} 8^{+} \mathrm{T}$ cells improves survival in human colorectal cancer. Clin Cancer Res. (2017) 23:384758. doi: 10.1158/1078-0432.CCR-16-2047

114. Eruslanov EB, Bhojnagarwala PS, Quatromoni JG, Stephen TL, Ranganathan A, Deshpande C, et al. Tumor-associated neutrophils stimulate $\mathrm{T}$ cell responses in early-stage human lung cancer. J Clin Invest. (2014) 124:546680. doi: $10.1172 /$ JCI77053

115. Singhal S, Bhojnagarwala PS, O'Brien S, Moon EK, Garfall AL, Rao AS, et al. Origin and role of a subset of tumor-associated neutrophils with antigenpresenting cell features in early-stage human lung cancer. Cancer Cell. (2016) 30:120-35. doi: 10.1016/j.ccell.2016.06.001

116. Khanh DT, Mekata E, Mukaisho K, Sugihara H, Shimizu T, Shiomi H, et al. Prognostic role of $\mathrm{CD} 10^{+}$myeloid cells in association with tumor budding at the invasion front of colorectal cancer. Cancer Sci. (2011) 102:172433. doi: 10.1111/j.1349-7006.2011.01987.x

117. Wikberg ML, Ling A, Li X, Öberg $\AA$, Edin S, Palmqvist R. Neutrophil infiltration is a favorable prognostic factor in early stages of colon cancer. Hum Pathol. (2017) 68:193-202. doi: 10.1016/j.humpath.2017.08.028

118. Berry RS, Xiong M-J, Greenbaum A, Mortaji P, Nofchissey RA, Schultz F, et al. High levels of tumor-associated neutrophils are associated with improved overall survival in patients with stage II colorectal cancer. PLoS ONE. (2017) 12:e0188799. doi: 10.1371/journal.pone.0188799

119. Jensen TO, Schmidt H, Møller HJ, Donskov F, Høyer M, Sjoegren P, et al. Intratumoral neutrophils and plasmacytoid dendritic cells indicate poor prognosis and are associated with pSTAT3 expression in AJCC stage I/II melanoma. Cancer. (2012) 118:2476-85. doi: 10.1002/cncr.26511

120. Carus A, Ladekarl M, Hager H, Nedergaard BS, Donskov F. Tumourassociated $\mathrm{CD}_{6} 6 \mathrm{~b}^{+}$neutrophil count is an independent prognostic factor for recurrence in localised cervical cancer. Br J Cancer. (2013) 108:211622. doi: 10.1038/bjc.2013.167

121. Wang T-T, Zhao Y-L, Peng L-S, Chen N, Chen W, Lv Y-P, et al. Tumouractivated neutrophils in gastric cancer foster immune suppression and disease progression through GM-CSF-PD-L1 pathway. Gut. (2017) 66:190011. doi: 10.1136/gutjnl-2016-313075

122. Clark SR, Ma AC, Tavener SA, McDonald B, Goodarzi Z, Kelly MM, et al. Platelet TLR4 activates neutrophil extracellular traps to ensnare bacteria in septic blood. Nat Med. (2007) 13:463-9. doi: 10.1038/nm1565

123. Caudrillier A, Kessenbrock K, Gilliss BM, Nguyen JX, Marques MB, Monestier $M$, et al. Platelets induce neutrophil extracellular traps in transfusion-related acute lung injury. J Clin Invest. (2012) 122:266171. doi: 10.1172/JCI61303

124. Aleyd E, Hout MWM van, Ganzevles SH, Hoeben KA, Everts V, Bakema JE, et al. IgA enhances NETosis and release of neutrophil extracellular traps by polymorphonuclear cells via Fc $\alpha$ receptor I. J Immunol. (2014) 192:2374-83. doi: 10.4049/jimmunol.1300261

125. Behnen M, Leschczyk C, Möller S, Batel T, Klinger M, Solbach W, et al. Immobilized immune complexes induce neutrophil extracellular trap release by human neutrophil granulocytes via Fc $\gamma$ RIIIB and Mac-1. J Immunol. (2014) 193:1954-65. doi: 10.4049/jimmunol.14 00478

126. Glodde N, Bald T, van den Boorn-Konijnenberg D, Nakamura K, O’Donnell JS, Szczepanski S, et al. Reactive neutrophil responses dependent on the receptor tyrosine kinase c-MET limit cancer immunotherapy. Immunity. (2017) 47:789-802.e9. doi: 10.1016/j.immuni.2017.09.012
127. Schmielau J, Finn OJ. Activated granulocytes and granulocyte-derived hydrogen peroxide are the underlying mechanism of suppression of T-cell function in advanced cancer patients. Cancer Res. (2001) 61:4756-60.

128. Singel KL, Emmons TR, Khan ANH, Mayor PC, Shen S, Wong JT, et al. Mature neutrophils suppress $\mathrm{T}$ cell immunity in ovarian cancer microenvironment. JCI Insight. (2019) 4:122311. doi: $10.1172 /$ jci.insight. 122311

129. Boross P, Lohse S, Nederend M, Jansen JHM, Tetering G van, Dechant M, et al. IgA EGFR antibodies mediate tumour killing in vivo. EMBO Mol Med. (2013) 5:1213-26. doi: 10.1002/emmm.201201929

130. Engblom C, Pfirschke C, Zilionis R, Da Silva Martins J, Bos SA, Courties G, et al. Osteoblasts remotely supply lung tumors with cancer-promoting SiglecFhigh neutrophils. Science. (2017) 358:eaal5081. doi: 10.1126/science.aal5081

131. Wu C, Ning H, Liu M, Lin J, Luo S, Zhu W, et al. Spleen mediates a distinct hematopoietic progenitor response supporting tumor-promoting myelopoiesis. J Clin Invest. (2018) 128:3425-38. doi: 10.1172/JCI97973

132. Dumortier A, Kirstetter P, Kastner P, Chan S. Ikaros regulates neutrophil differentiation. Blood. (2003) 101:2219-26. doi: 10.1182/blood-2002-05-1336

133. Papathanasiou P, Perkins AC, Cobb BS, Ferrini R, Sridharan R, Hoyne GF, et al. Widespread failure of hematolymphoid differentiation caused by a recessive niche-filling allele of the Ikaros transcription factor. Immunity. (2003) 19:131-44. doi: 10.1016/S1074-7613(03)00168-7

134. Bronte V, Pittet $M J$. The spleen in local and systemic regulation of immunity. Immunity. (2013) 39:806-18. doi: 10.1016/j.immuni.2013.10.010

135. Eggert T, Wolter K, Ji J, Ma C, Yevsa T, Klotz S, et al. Distinct functions of senescence-associated immune responses in liver tumor surveillance and tumor progression. Cancer Cell. (2016) 30:533-47. doi: 10.1016/j.ccell.2016.09.003

136. Waight JD, Hu Q, Miller A, Liu S, Abrams SI. Tumor-derived G-CSF facilitates neoplastic growth through a granulocytic myeloidderived suppressor cell-dependent mechanism. PLoS ONE. (2011) 6:e27690. doi: 10.1371/journal.pone.0027690

137. Kowanetz M, Wu X, Lee J, Tan M, Hagenbeek T, Qu X, et al. Granulocytecolony stimulating factor promotes lung metastasis through mobilization of Ly6G+Ly6C+ granulocytes. Proc Natl Acad Sci USA. (2010) 107:2124855. doi: 10.1073/pnas.1015855107

138. Bendall LJ, Bradstock KF. G-CSF: from granulopoietic stimulant to bone marrow stem cell mobilizing agent. Cytokine Growth Factor Rev. (2014) 25:355-67. doi: 10.1016/j.cytogfr.2014.07.011

139. Groblewska M, Mroczko B, Wereszczynska-Siemiatkowska U, Myśliwiec P, Kedra B, Szmitkowski M. Serum levels of granulocyte colonystimulating factor (G-CSF) and macrophage colony-stimulating factor (MCSF) in pancreatic cancer patients. Clin Chem Lab Med. (2007) 45:304. doi: 10.1515/CCLM.2007.025

140. Mroczko B, Szmitkowski M, Okulczyk B. Granulocyte-colony stimulating factor (G-CSF) and macrophagecolony stimulating factor (M-CSF) in colorectal cancer patients. Clin Chem Lab Med. (2002) 40:351-5. doi: 10.1515/CCLM.2002.056

141. Mroczko B, Szmitkowski M, Niklinski J. Granulocyte-Colony stimulating factor and macrophage-colony stimulating factor in patients with non-small-cell lung cancer. Clin Chem Lab Med. (2001) 39:374-9. doi: 10.1515/CCLM.2001.059

142. Nishimura $\mathrm{K}$, Higashino M, Hara T, Oka T. Bladder cancer producing granulocyte colony-stimulating factor: a case report. Int J Urol. (1996) 3:152-4. doi: 10.1111/j.1442-2042.1996.tb00502.x

143. Asano T, Morimoto S, Kitami Y, Miyauchi T, Sakai K, Takagi K. [Bladder cancer producing granulocyte colony-stimulating factor (G-CSF): a case report]. Hinyokika Kiyo. (2002) 48:495-8.

144. Nasu K, Inoue C, Takai N, Kashima K, Miyakawa I. Squamous cell carcinoma of the cervix producing granulocyte colony-stimulating factor. Obstet Gynecol. (2004) 104:1086-8. doi: 10.1097/01.AOG.0000141552.87313.c8

145. Yeo B, Redfern AD, Mouchemore KA, Hamilton JA, Anderson RL. The dark side of granulocyte-colony stimulating factor: a supportive therapy with potential to promote tumour progression. Clin Exp Metastasis. (2018) 35:255-67. doi: 10.1007/s10585-018-9917-7

146. Papaldo P, Lopez M, Cortesi E, Cammilluzzi E, Antimi M, Terzoli E, et al. Addition of either lonidamine or granulocyte colony-stimulating factor 
does not improve survival in early breast cancer patients treated with high-dose epirubicin and cyclophosphamide. J Clin Oncol. (2003) 21:34628. doi: 10.1200/JCO.2003.03.034

147. Panopoulos AD, Watowich SS. Granulocyte colony-stimulating factor: molecular mechanisms of action during steady state and "emergency" hematopoiesis. Cytokine. (2008) 42:277-88. doi: 10.1016/j.cyto.2008.03.002

148. Akbay EA, Koyama S, Liu Y, Dries R, Bufe LE, Silkes M, et al. Interleukin-17A promotes lung tumor progression through neutrophil attraction to tumor sites and mediating resistance to PD-1 blockade. J Thorac Oncol. (2017) 12:1268-79. doi: $10.1016 /$ j.jtho.2017.04.017

149. Wu J, Du J, Liu L, Li Q, Rong W, Wang L, et al. Elevated pretherapy serum IL17 in primary hepatocellular carcinoma patients correlate to increased risk of early recurrence after curative hepatectomy. PLoS ONE. (2012) 7:e50035. doi: 10.1371/journal.pone.0050035

150. Xu C, Hao K, Yu L, Zhang X. Serum interleukin-17 as a diagnostic and prognostic marker for non-small cell lung cancer. Biomarkers. (2014) 19:287-90. doi: 10.3109/1354750X.2014.908954

151. Pan B, Che D, Cao J, Shen J, Jin S, Zhou Y, et al. Interleukin-17 levels correlate with poor prognosis and vascular endothelial growth factor concentration in the serum of patients with non-small cell lung cancer. Biomarkers. (2015) 20:232-9. doi: 10.3109/1354750X.2015.1068853

152. Cacalano G, Lee J, Kikly K, Ryan AM, Pitts-Meek S, Hultgren B, et al. Neutrophil and B cell expansion in mice that lack the murine IL-8 receptor homolog. Science. (1994) 265:682-4. doi: 10.1126/science.8036519

153. Martin C, Burdon PCE, Bridger G, Gutierrez-Ramos JC, Williams TJ, Rankin SM. Chemokines acting via CXCR2 and CXCR4 control the release of neutrophils from the bone marrow and their return following senescence. Immunity. (2003) 19:583-93. doi: 10.1016/S1074-7613(03)00263-2

154. Eash KJ, Greenbaum AM, Gopalan PK, Link DC. CXCR2 and CXCR4 antagonistically regulate neutrophil trafficking from murine bone marrow. J Clin Invest. (2010) 120:2423-31. doi: 10.1172/JCI41649

155. Devi S, Wang Y, Chew WK, Lima R, A-González N, Mattar CNZ, et al. Neutrophil mobilization via plerixafor-mediated CXCR4 inhibition arises from lung demargination and blockade of neutrophil homing to the bone marrow. J Exp Med. (2013) 210:2321-36. doi: 10.1084/jem.20130056

156. Gong L, Cumpian AM, Caetano MS, Ochoa CE, De la Garza MM, Lapid DJ, et al. Promoting effect of neutrophils on lung tumorigenesis is mediated by CXCR2 and neutrophil elastase. Mol Cancer. (2013) 12:154. doi: 10.1186/1476-4598-12-154

157. Steele CW, Karim SA, Leach JDG, Bailey P, Upstill-Goddard R, Rishi L, et al. CXCR2 inhibition profoundly suppresses metastases and augments immunotherapy in pancreatic ductal adenocarcinoma. Cancer Cell. (2016) 29:832-45. doi: 10.1016/j.ccell.2016.04.014

158. Luppi F, Longo AM, de Boer WI, Rabe KF, Hiemstra PS. Interleukin-8 stimulates cell proliferation in non-small cell lung cancer through epidermal growth factor receptor transactivation. Lung Cancer Amst Neth. (2007) 56:25-33. doi: 10.1016/j.lungcan.2006.11.014

159. Saintigny P, Massarelli E, Lin S, Ahn Y-H, Chen Y, Goswami S, et al. CXCR2 expression in tumor cells is a poor prognostic factor and promotes invasion and metastasis in lung adenocarcinoma. Cancer Res. (2013) 73:57182. doi: 10.1158/0008-5472.CAN-12-0263

160. Zhu YM, Webster SJ, Flower D, Woll PJ. Interleukin-8/CXCL8 is a growth factor for human lung cancer cells. Br J Cancer. (2004) 91:19706. doi: $10.1038 /$ sj.bjc. 6602227

161. Eash KJ, Means JM, White DW, Link DC. CXCR4 is a key regulator of neutrophil release from the bone marrow under basal and stress granulopoiesis conditions. Blood. (2009) 113:4711-9. doi: 10.1182/blood-2008-09-177287

162. Jung K, Heishi T, Incio J, Huang Y, Beech EY, Pinter M, et al. Targeting CXCR4-dependent immunosuppressive Ly6Clow monocytes improves antiangiogenic therapy in colorectal cancer. Proc Natl Acad Sci USA. (2017) 114:10455-60. doi: 10.1073/pnas.1710754114

163. Xue L, Mao X, Ren L, Chu X. Inhibition of CXCL12/CXCR4 axis as a potential targeted therapy of advanced gastric carcinoma. Cancer Med. (2017) 6:1424-36. doi: 10.1002/cam4.1085

164. Redjal N, Chan JA, Segal RA, Kung AL. CXCR4 inhibition synergizes with cytotoxic chemotherapy in gliomas. Clin Cancer Res. (2006) 12:676571. doi: 10.1158/1078-0432.CCR-06-1372
165. Taromi S, Kayser G, Catusse J, von Elverfeldt D, Reichardt W, Braun F, et al. CXCR4 antagonists suppress small cell lung cancer progression. Oncotarget. (2016) 7:85185-95. doi: 10.18632/oncotarget.13238

166. Domanska UM, Timmer-Bosscha H, Nagengast WB, Oude Munnink TH, Kruizinga RC, Ananias HJK, et al. CXCR4 inhibition with AMD3100 sensitizes prostate cancer to docetaxel chemotherapy. Neoplasia. (2012) 14:709-18. doi: 10.1593/neo.12324

167. Baltschukat S, Engstler BS, Huang A, Hao H-X, Tam A, Wang HQ, et al. Capmatinib (INC280) is active against models of non-small cell lung cancer and other cancer types with defined mechanisms of MET activation. Clin Cancer Res. (2019) 25:3164-75. doi: 10.1158/1078-0432.CCR-18-2814

168. Finisguerra V, Di Conza G, Di Matteo M, Serneels J, Costa S, Thompson AAR, et al. MET is required for the recruitment of anti-tumoural neutrophils. Nature. (2015) 522:349-53. doi: 10.1038/nature14407

169. Dominguez GA, Condamine T, Mony S, Hashimoto A, Wang F, Liu Q, et al. Selective targeting of myeloid-derived suppressor cells in cancer patients using DS-8273a, an agonistic TRAIL-R2 antibody. Clin Cancer Res. (2016) 23:2942-50. doi: 10.1158/1538-7445.AM2017-CT095

170. Vincent J, Mignot G, Chalmin F, Ladoire S, Bruchard M, Chevriaux A, et al. 5-Fluorouracil selectively kills tumor-associated myeloid-derived suppressor cells resulting in enhanced T cell-dependent antitumor immunity. Cancer Res. (2010) 70:3052-61. doi: 10.1158/0008-5472.CAN-09-3690

171. Bruchard M, Mignot G, Derangère V, Chalmin F, Chevriaux A, Végran F, et al. Chemotherapy-triggered cathepsin B release in myeloid-derived suppressor cells activates the Nlrp3 inflammasome and promotes tumor growth. Nat Med. (2013) 19:57-64. doi: 10.1038/nm.2999

172. Wang Z, Till B, Gao Q. Chemotherapeutic agent-mediated elimination of myeloid-derived suppressor cells. Oncoimmunology. (2017) 6:e1331807. doi: 10.1080/2162402X.2017.1331807

173. Fleming V, Hu X, Weber R, Nagibin V, Groth C, Altevogt $\mathrm{P}$, et al. Targeting myeloid-derived suppressor cells to bypass tumor-induced immunosuppression. Front Immunol. (2018) 9:398. doi: 10.3389/fimmu.2018.00398

174. Patil MD, Bhaumik J, Babykutty S, Banerjee UC, Fukumura D. Arginine dependence of tumor cells: targeting a chink in cancer's armor. Oncogene. (2016) 35:4957-72. doi: 10.1038/onc.2016.37

175. García-Navas R, Munder M, Mollinedo F. Depletion of L-arginine induces autophagy as a cytoprotective response to endoplasmic reticulum stress in human $\mathrm{T}$ lymphocytes. Autophagy. (2012) 8:1557-76. doi: 10.4161/auto.21315

176. Geiger R, Rieckmann JC, Wolf T, Basso C, Feng Y, Fuhrer T, et al. L-arginine modulates $\mathrm{T}$ cell metabolism and enhances survival and anti-tumor activity. Cell. (2016) 167:829-42.e13. doi: 10.1016/j.cell.2016.09.031

177. Steggerda SM, Bennett MK, Chen J, Emberley E, Huang T, Janes JR, et al. Inhibition of arginase by CB-1158 blocks myeloid cell-mediated immune suppression in the tumor microenvironment. J Immunother Cancer. (2017) 5:101. doi: 10.1186/s40425-017-0308-4

178. Lam TL, Wong GKY, Chong HC, Cheng PNM, Choi SC, Chow TL, et al. Recombinant human arginase inhibits proliferation of human hepatocellular carcinoma by inducing cell cycle arrest. Cancer Lett. (2009) 277:91100. doi: 10.1016/j.canlet.2008.11.031

179. Lam T-L, Wong GKY, Chow H-Y, Chong H-C, Chow T-L, Kwok S-Y, et al. Recombinant human arginase inhibits the in vitro and in vivo proliferation of human melanoma by inducing cell cycle arrest and apoptosis. Pigment Cell Melanoma Res. (2011) 24:366-76. doi: 10.1111/j.1755-148X.2010.00798.x

180. Chow AKM, Ng L, Sing Li H, Cheng CW, Lam CSC, Yau TCC, et al. Anti-tumor efficacy of a recombinant human arginase in human hepatocellular carcinoma. Curr Cancer Drug Targets. (2012) 12:123343. doi: $10.2174 / 156800912803988002$

181. Li L, Wang Y, Chen J, Cheng B, Hu J, Zhou Y, et al. An engineered arginase FC protein inhibits tumor growth in vitro and in vivo. Evid Based Complement Alternat Med. (2013) 2013:423129. doi: 10.1155/2013/423129

182. Wang Z, Shi X, Li Y, Fan J, Zeng X, Xian Z, et al. Blocking autophagy enhanced cytotoxicity induced by recombinant human arginase in triple-negative breast cancer cells. Cell Death Dis. (2014) 5:e1563. doi: 10.1038/cddis.2014.503

183. Agnello G, Alters SE, Lowe DG, Rowlinson SW. Abstract 3964: reducing systemic arginine with arginase (AEB1102) therapy does not suppress the 
immune response induced by anti-PD-1 and anti-PD-L1, and exerts an additive anti-tumor and synergistic survival benefit. Cancer Res. (2017) 77:3964. doi: 10.1158/1538-7445.AM2017-3964

184. Agnello G, Badeaux MD, Enzler D, Priddy L, Wiggins JF, Daige CL, et al. Abstract 869: depletion of blood arginine with pegzilarginase (AEB1102) in combination with anti-PD-L1 increases tumor infiltration by immune cells and enhances antitumor activity. Cancer Res. (2018) 78:869. doi: 10.1158/1538-7445.AM2018-869

185. Zhou S-L, Zhou Z-J, Hu Z-Q, Huang X-W, Wang Z, Chen E-B, et al. Tumor-associated neutrophils recruit macrophages and T-regulatory cells to promote progression of hepatocellular carcinoma and resistance to sorafenib. Gastroenterology. (2016) 150:1646-58.e17. doi: 10.1053/j.gastro.2016.02.040

186. Ko JS, Zea AH, Rini BI, Ireland JL, Elson $\mathrm{P}$, Cohen $\mathrm{P}$, et al. Sunitinib mediates reversal of myeloid-derived suppressor cell accumulation in renal cell carcinoma patients. Clin Cancer Res. (2009) 15:214857. doi: 10.1158/1078-0432.CCR-08-1332

187. Ko JS, Rayman P, Ireland J, Swaidani S, Li G, Bunting KD, et al. Direct and differential suppression of myeloid-derived suppressor cell subsets by sunitinib is compartmentally constrained. Cancer Res. (2010) 70:352636. doi: 10.1158/0008-5472.CAN-09-3278

188. Finke J, Ko J, Rini B, Rayman P, Ireland J, Cohen P. MDSC as a mechanism of tumor escape from sunitinib mediated anti-angiogenic therapy. Int Immunopharmacol. (2011) 11:853-8. doi: 10.1016/j.intimp.2011.01.030

189. Draghiciu O, Nijman HW, Hoogeboom BN, Meijerhof $T$, Daemen T. Sunitinib depletes myeloid-derived suppressor cells and synergizes with a cancer vaccine to enhance antigen-specific immune responses and tumor eradication. Oncoimmunology. (2015) 4:e989764. doi: 10.4161/2162402X.2014.989764

190. Corrales L, Ajona D, Rafail S, Lasarte JJ, Riezu-Boj JI, Lambris JD, et al. Anaphylatoxin C5a creates a favorable microenvironment for lung cancer progression. J Immunol. (2012) 189:467483. doi: 10.4049/jimmunol.1201654

191. Ajona D, Ortiz-Espinosa S, Moreno H, Lozano T, Pajares MJ, Agorreta J, et al. A combined PD-1/C5a blockade synergistically protects against lung cancer growth and metastasis. Cancer Discov. (2017) 7:694703. doi: 10.1158/2159-8290.CD-16-1184

192. Medler TR, Murugan D, Horton W, Kumar S, Cotechini T, Forsyth $\mathrm{AM}$, et al. Complement $\mathrm{C} 5 \mathrm{a}$ fosters squamous carcinogenesis and limits T cell response to chemotherapy. Cancer Cell. (2018) 34:56178.e6. doi: 10.1016/j.ccell.2018.09.003

193. Demaria O, Rubio L, Belaid N, Habif G, Bonnafous C, Zerbib R, et al. Characterization of anti-C5aR antibodies for specific Poster \# B184 targeting of myeloid cells and neutrophils in the TME.1. In: Third CRI-CIMT-EATIAACR International Cancer Immunotherapy Conference. Frankfurt (2017).

194. Kortylewski M, Kujawski M, Wang T, Wei S, Zhang S, PilonThomas S, et al. Inhibiting Stat3 signaling in the hematopoietic system elicits multicomponent antitumor immunity. Nat Med. (2005) 11:1314-21. doi: 10.1038/nm1325

195. Rosborough BR, Mathews LR, Matta BM, Liu Q, Raïch-Regué D, Thomson AW, et al. Cutting edge: Flt3 ligand mediates STAT3-independent expansion but STAT3-dependent activation of myeloid-derived suppressor cells. $J$ Immunol. (2014) 192:3470-3. doi: 10.4049/jimmunol.1300058

196. Zhou J, Qu Z, Sun F, Han L, Li L, Yan S, et al. Myeloid STAT3 promotes lung tumorigenesis by transforming tumor immunosurveillance into tumor-promoting inflammation. Cancer Immunol Res. (2017) 5:25768. doi: 10.1158/2326-6066.CIR-16-0073
197. Su Y-L, Banerjee S, White SV, Kortylewski M. STAT3 in tumor-associated myeloid cells: multitasking to disrupt immunity. Int J Mol Sci. (2018) 19:E1803. doi: 10.3390/ijms19061803

198. Kujawski M, Kortylewski M, Lee H, Herrmann A, Kay H, Yu H. Stat3 mediates myeloid cell-dependent tumor angiogenesis in mice. J Clin Invest. (2008) 118:3367-77. doi: 10.1172/JCI35213

199. Kortylewski M, Moreira D. Myeloid cells as a target for oligonucleotide therapeutics: turning obstacles into opportunities. Cancer Immunol Immunother. (2017) 66:979-88. doi: 10.1007/s00262-017-1966-2

200. Hossain F, Al-Khami AA, Wyczechowska D, Hernandez C, Zheng $\mathrm{L}$, Reiss $\mathrm{K}$, et al. Inhibition of fatty acid oxidation modulates immunosuppressive functions of myeloid-derived suppressor cells and enhances cancer therapies. Cancer Immunol Res. (2015) 3:1236-47. doi: 10.1158/2326-6066.CIR-15-0036

201. Al-Khami AA, Zheng L, Del Valle L, Hossain F, Wyczechowska D, Zabaleta J, et al. Exogenous lipid uptake induces metabolic and functional reprogramming of tumor-associated myeloid-derived suppressor cells. Oncoimmunology. (2017) 6:e1344804. doi: 10.1080/2162402X.2017. 1344804

202. Veglia F, Tyurin VA, Blasi M, De Leo A, Kossenkov AV, Donthireddy L, et al. Fatty acid transport protein 2 reprograms neutrophils in cancer. Nature. (2019) 569:73-8. doi: 10.1038/s41586-019-1118-2

203. Wenzel SE, Kamada AK. Zileuton: the first 5lipoxygenase inhibitor for the treatment of asthma. Ann Pharmacother. (1996) 30:858-64. doi: 10.1177/1060028096030 00725

204. Najmeh S, Cools-Lartigue J, Rayes RF, Gowing S, Vourtzoumis P, Bourdeau F, et al. Neutrophil extracellular traps sequester circulating tumor cells via $\beta 1$-integrin mediated interactions. Int J Cancer. (2017) 140:232130. doi: 10.1002/ijc.30635

205. Aleyd E, Heineke MH, van Egmond M. The era of the immunoglobulin A Fc receptor FcoRI; its function and potential as target in disease. Immunol Rev. (2015) 268:123-38. doi: 10.1111/imr. 12337

206. Kasikara C, Davra V, Calianese D, Geng K, Spires TE, Quigley M, et al. Pan-TAM tyrosine kinase inhibitor BMS-777607 enhances anti-PD-1 mAb efficacy in a murine model of triple-negative breast cancer. Cancer Res. (2019) 79:2669-83. doi: 10.1158/0008-5472.CAN-18-2614

207. Angelova M, Mlecnik B, Vasaturo A, Bindea G, Fredriksen T, Lafontaine L, et al. Evolution of metastases in space and time under immune selection. Cell. (2018) 175:751-65.e16. doi: 10.1016/j.cell.2018. 09.018

208. Dixon SJ, Lemberg KM, Lamprecht MR, Skouta R, Zaitsev EM, Gleason CE, et al. Ferroptosis: an iron-dependent form of nonapoptotic cell death. Cell. (2012) 149:1060-72. doi: 10.1016/j.cell.2012.03.042

Conflict of Interest Statement: The authors declare that the research was conducted in the absence of any commercial or financial relationships that could be construed as a potential conflict of interest.

Copyright (C) 2019 Lecot, Sarabi, Pereira Abrantes, Mussard, Koenderman, Caux, Bendriss-Vermare and Michallet. This is an open-access article distributed under the terms of the Creative Commons Attribution License (CC BY). The use, distribution or reproduction in other forums is permitted, provided the original author(s) and the copyright owner(s) are credited and that the original publication in this journal is cited, in accordance with accepted academic practice. No use, distribution or reproduction is permitted which does not comply with these terms. 